POLY(4-STYRENESULFONIC ACID-CO-MALEIC ACID) STABILIZED NICKEL(0) NANOPARTICLES: HIGHLY ACTIVE AND COST EFFECTIVE CATALYST IN HYDROGEN GENERATION FROM THE HYDROLYSIS OF HYDRAZINE BORANE

A THESIS SUBMITTED TO

THE GRADUATE SCHOOL OF NATURAL AND APPLIED SCIENCES

$\mathrm{OF}$

MIDDLE EAST TECHNICAL UNIVERSITY

BY

SELIN ŞENCANLI

IN PARTIAL FULFILLMENT OF THE REQUIREMENTS

FOR

THE DEGREE OF MASTER OF SCIENCE

IN

CHEMISTRY

MAY 2013 

Approval of the thesis:

\section{POLY(4-STYRENESULFONIC ACID-CO-MALEIC ACID) STABILIZED NICKEL(0) NANOPARTICLES: HIGHLY ACTIVE AND COST EFFECTIVE CATALYST IN HYDROGEN GENERATION FROM THE HYDROLYSIS OF HYDRAZINE BORANE}

submitted by SELIN ŞENCANLI in partial fulfillment of the requirements for the degree of Master of Science in Chemistry Department, Middle East Technical University by,

Prof. Dr. Canan Özgen

Dean, Graduate School of Natural and Applied Sciences

Prof. Dr. İlker Özkan

Head of Department, Chemistry

Prof. Dr. Saim Özkar

Supervisor, Chemistry Dept., METU

\section{Examining Committee Members:}

Prof. Dr. Ceyhan Kayran

Chemistry Dept., METU

Prof. Dr. Saim Özkar

Chemistry Dept., METU

Prof. Dr. Göknur Bayram

Chemical Engineering Dept., METU

Assoc. Prof. Dr. Ayşen Yılmaz

Chemistry Dept., METU

Assist. Prof. Dr. Emren Nalbant Esentürk

Chemistry Dept., METU

Date: $\quad 27.05 .2013$ 
I hereby declare that all information in this document has been obtained and presented in accordance with academic rules and ethical conduct. I also declare that, as required by these rules and conduct, I have fully cited and referenced all material and results that are not original to this work.

Name, Last name: Selin ŞENCANLI

Signature: 


\title{
ABSTRACT \\ POLY(4-STYRENESULFONIC ACID-CO-MALEIC ACID) STABILIZED NICKEL(0) NANOPARTICLES: HIGHLY ACTIVE AND COST EFFECTIVE CATALYST IN HYDROGEN GENERATION FROM THE HYDROLYSIS OF HYDRAZINE BORANE
}

\author{
Şencanl, Selin \\ M.Sc., Department of Chemistry \\ Supervisor: Prof. Dr. Saim Özkar
}

May 2013, 49 pages

\begin{abstract}
In general, the catalytic activity of transition metal nanoparticles increases as the fraction of atoms on the surface increases with decreasing particle size. However, transition metal nanoparticles tend to agglomerate into bulk metal in solution. In order to prevent agglomeration stabilizing agent can be used in the formation of stable transition metal nanoparticles in solution. In this study, one of the most available commercial polymers was used to provide steric stabilization during the formation of stable metal nanoparticles. In this dissertation, we report the in-situ preparation and characterization of poly(4-styrenesulfonic acid-co-maleic acid) (PSSMA) stabilized nickel(0) nanoparticles and their catalytic activity in hydrogen generation from the hydrolysis of hydrazine borane (HB). PSSMA stabilized nickel(0) nanoparticles (PSSMA-Ni NPs) were in-situ prepared from reduction of nickel(II) chloride by hydrazine borane in the presence of PSSMA as stabilizer. Nickel(0) nanoparticles with an average particle size of $8.3 \pm 2.3 \mathrm{~nm}$ were isolated from reaction medium by centrifugation and characterized by using TEM, EDX, XRD, XPS and UV-Vis techniques. PSSMA-Ni NPs were found as highly active and cost effective catalyst. They provide 1600 turnovers over $18 \mathrm{~h}$ for the hydrolysis of $\mathrm{HB}$ at room temperature before deactivation. The kinetics of the hydrolysis of HB catalyzed by PSSMA-Ni NPs were studied depending on the catalyst concentration, substrate concentration and temperature and the apparent activation parameters $\left(\mathrm{Ea}^{\text {app }}, \Delta \mathrm{H}^{\#, \text { app }}\right.$ and $\left.\Delta \mathrm{S}^{\#, \text { app }}\right)$ of the catalytic reaction were calculated. This is the first study on the hydrolysis of HB in the presence of polymer stabilized monometallic nickel based catalyst which is higly active and cost effective.
\end{abstract}

Keywords: Nickel Nanoparticles, Poly(4-styrene sulfonicacid-co-maleic acid), Catalyst, Hydrolysis of Hydrazine Borane, Hydrogen Generation 
ÖZ

\title{
POLY(4-STYRENESULFONIC ACID-CO-MALEIC ACID) İLE KARARLAŞTIRILMIŞ NİKEL(0) NANOPARÇACIKLARI:HIDDAZIN BORANIN HİDROLIZIINDEN HİDROJEN ÜRETIMINDE OLDUKÇA AKTIF VE EKONOMIK KATALIZÖR
}

\author{
Şencanl, Selin \\ Yüksek Lisans, Kimya Bölümü \\ Tez Yöneticisi: Prof. Dr. Saim Özkar
}

Mayıs 2013, 49 pages

\begin{abstract}
Geçiş metal nanoparçacıklarının katalitik aktiviteleri, yüzeydeki atom sayısı arttıkça ve parçacık boyutları küçüldükçe artmaktadır. Ancak, metal nanoparçacıklar topaklanma ve çözelti içinde metal külçe oluşturma eğilimindedirler. Kararlı geçiş metal nanoparçacıklarının oluşumunda çözelti içinde oluşabilecek topaklanmayı önlemek için kararlılaştırıcılar kullanılır. Bu tezde, poli(4-sitiren sulfonikasit-co-maleyik asit) (PSSMA) ile kararlılaştırılmış nikel(0) nanoparçacıkların hazırlanması, tanımlanması, hazırlanan katalizörün hidrazin boranın hidroliz tepkimesinde kullanılarak elde edilen katalitik aktivite ve kinetik çalışma verileri raporlanmıştır. PSSMA ile kararlılaştırılmış nikel(0) nanoparçacıkları (PSSMA-Ni), nikel(II) klorürün PSSMA varlığında hidrazin boran ile indirgenmesi sonucunda hazırlandı. Ortalama $8.3 \pm 2.3 \mathrm{~nm}$ parçacık boyutuna sahip olan nanoparçacıklar santrifüjleme yöntemi ile tepkime ortamından izole edildi. İzole edilen nanoparçacıklar TEM, EDX, XRD, XPS ve UV-görünür teknikleri kullanılarak tanımlandı. Yapılan çalışmalar sonunda nikel(0) nanokümelerinin katalitik aktivite bakımından oldukça etkin ve maliyet açısından uygun olduğu tespit edildi. Oldukça aktif bulunan PSSMA-Ni nanoparçacıkları, oda sıcaklığında hidrazin boranın hidrolizi tepkimesinde katalizör olarak kullanıldı ve etkinliklerini yitirmeden 18 saat boyunca 1600 toplam çevrim sayısı sağladı. PSSMA-Ni nanoparçacıkları ile katalizlenen HB'nın hidroliz tepkimesinin kinetiği; katalizör derişimine, tepken derişimine ve sıcaklığa bağlı olarak çalışıldı. Katalitik tepkimelerin aktivasyon parametreleri ( $\mathrm{Ea}^{\mathrm{app}}, \Delta \mathrm{H}^{\# \text {,app }}$ and $\Delta \mathrm{S}^{\# \text {,app }}$ ) elde edilen kinetik veriler kullanılarak hesaplandı. Bu çalışma, polimer ile kararlaştırılmış, nikel içerikli, monometalik, oldukça aktif ve ucuz katalizör varlığında HB'nın hidrolizinden elde edilen hidrojen üretimi ile ilgili yapılan ilk çalışma olması açısından önem taşımaktadır.
\end{abstract}

Anahtar Kelimeler: Nikel Nanoparçacıkları, Poli(4-sitiren sulfonikasit-co-maleyik asit), Katalizör, Hidrazin Boranın Hidrolizi, Hidrojen Üretimi 
To My Family, 


\section{ACKNOWLEDGEMENT}

I would like to express my ingenuous thanks to Prof. Dr. Saim Özkar for his precious support, guidance and encouragement, especially in desperate times, during my graduate studies and in completion of this dissertation. I am profoundly honored to have a chance to work with him, and I appreciate all his contributions.

My appreciation and thanks to Dr. Senem Karahan for her guidance, valuable advice, motivation, supports and positive attitude towards me during my thesis studies.

I am also grateful to the Assist. Prof. Dr. Önder Metin for his advices and supports.

I would like to express my thanks to my labmates Derya Çelik, Serdar Akbayrak, Tuğçe Ayvalı, Murat Rakap, Ebru Ünel and Salim Çalışkan for their motivation and friendship during my studies.

I would like to give my special thanks to Ayşegül Hisar, İlke İleri, Şevki Can Cevher Deniz Çakal, Gülşah Güvenbaş, Oğuzhan Kaplan and Cem Özten for their valuable motivation, support and precious friendship.

I would like to express my thanks to my siblings Seda Şencanlı Demirci and Sibel Şencanlı Atalay and brother in law Okan Atalay and Cem Demirci for their love, patience, moral support and encouragement in every moment of my life and my nephew İpek Atalay for making me happy by her just a little smile.

The last but not the least, my special appreciation and great gratitude is devoted to my parents for their endless love, patience and moral support during my master studies. I dedicate this thesis to them. 


\section{TABLE OF CONTENTS}

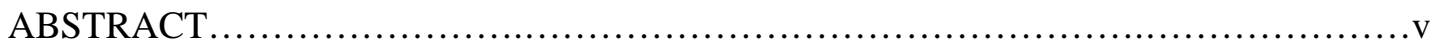

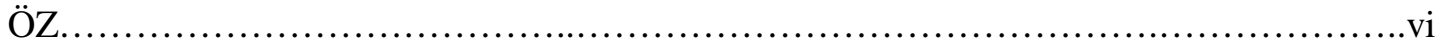

ACKNOWLEDGMENT .....................................................................

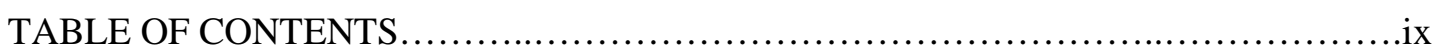

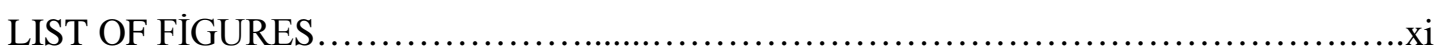

LIST OF ABBREVIATIONS..........................................................

CHAPTERS

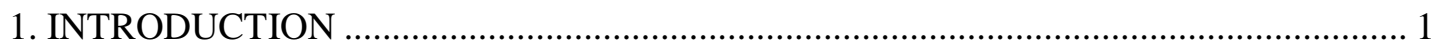

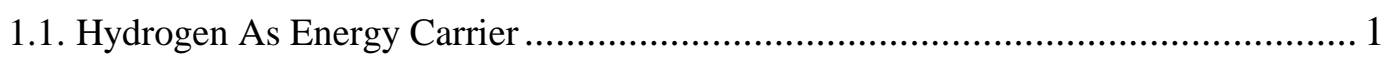

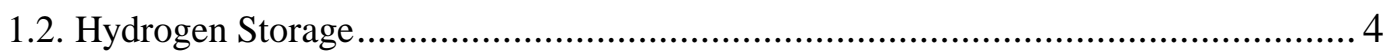

1.3. Hydrazine Borane and Its Hydrolysis Reaction ................................................ 6

1.4. The Motivation of the Dissertation................................................................ 9

2. CATALYSIS AND TRANSITION METAL(0) NANOPARTICLES .............................. 11

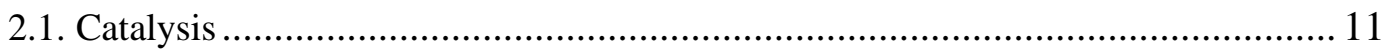

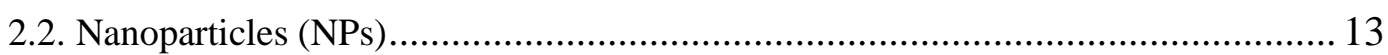

2.2.1.Transition Metal Nanoparticles: Suitable Catalyst for Hydrogen

Generation............................................................

2.2.2. Synthesis and Stabilization of Transition Metal Nanoparticles .......................... 15

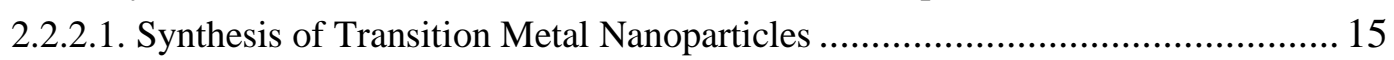

2.2.2.2. Stabilization of Transition Metal Nanoparticles............................................ 16

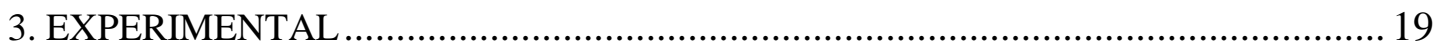

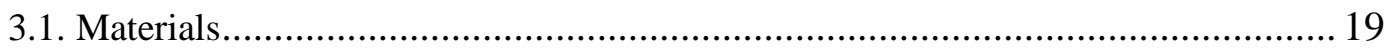

3.2. In Situ Formation of PSSMA Stabilized Nickel(0) Nanoparticles and Catalytic Hydrolysis of Hydrazine Borane with Hydrogen Generation Data Handling................. 19

3.3. Characterization of PSSMA Stabilized Nickel(0) Nanoparticles............................ 20

3.4. Synthesis and Characterization of Hydrazine Borane ........................................ 21

3.5. Kinetic Study of PSSMA Stabilized Nickel(0) Nanoparticles in Catalytic Hydrolysis of Hydrazine Borane ............................................................................................. 21

3.6. Effect of PSSMA Concentration on the Catalytic Activity of Nickel(0) Nanoparticles..................................................................................... 22

3.7. Determination of Activation Parameters of Hydrolysis of HB Catalyzed by PSSMA Stabilized Nickel(0) Nanoparticles ......................................................................... 22

3.8. Determination of the Catalytic Life Time of PSSMA-Ni in Hydrolysis of

HB.................................................................22

3.9. Carbon Disulfide $\left(\mathrm{CS}_{2}\right)$ Poisoning of PSSMA-Ni and Its Monitoring in the Catalytic

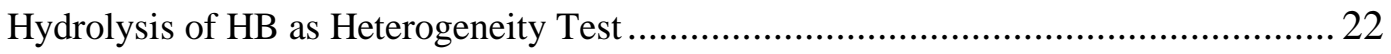

3.10. Determination of the Liberated $\mathrm{NH}_{3}$ Gas ...................................................... 22

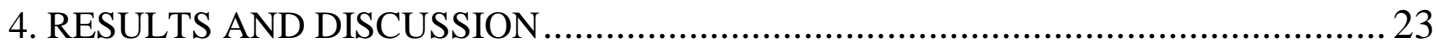


4.1. In Situ Formation, Isolation and Characterization of PSSMA Stabilized Nickel(0) Nanoparticles in Hydrolysis of Hydrazine Borane ...................................................22

4.2. Kinetic Evidence for the Formation of the PSSMA Stabilized Nickel(0)

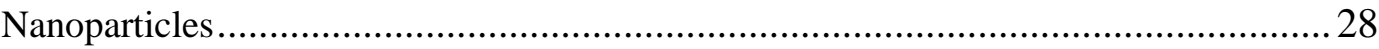

4.3. Kinetics of Catalytic Hydrolysis of Hydrazine Borane in the Presence of PSSMA

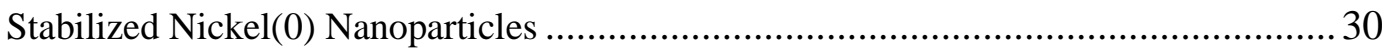

4.4. Catalytic Lifetime of PSSMA-Ni in Hydrolysis of Hydrazine Borane.................... 36

4.5. Carbon Disulfide $\left(\mathrm{CS}_{2}\right)$ Poisoning of PSSMA-Ni and Its Monitoring in the Catalytic

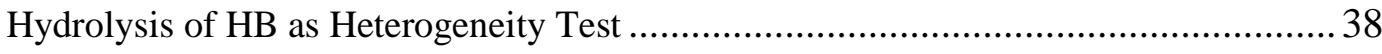

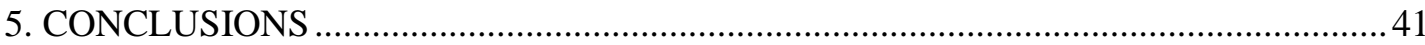

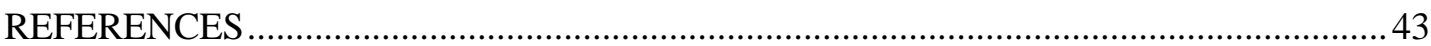




\section{LIST OF FIGURES}

\section{FIGURES}

Figure 1- Primary Energy Consumption by Source and Sector ....................................... 1

Figure 2. Renewable Energy as Share of Total Primary Energy Consumption....................... 2

Figure 3. Hydrogen: Promissing Energy Carrier ............................................................ 3

Figure 4. Volumetric and gravimetric energy densities of various energy storage materials..5

Figure 5. The structure of poly(4-styrenesulfonic acid-co-maleic acid) ............................... 8

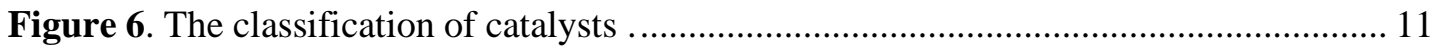

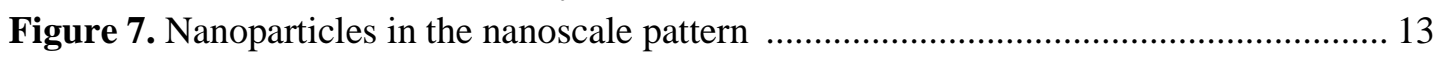

Figure 8. The change in percentage of surface iron atoms depending on the size of iron(0)

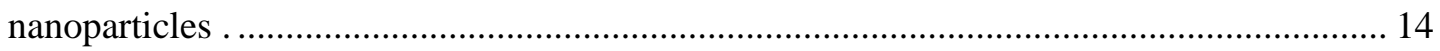

Figure 9. Formation of nanoparticles via reduction of metal salt precursors ....................... 15

Figure 10. Schematic representation of the electrostatic stabilization of transition metal nanoparticles

Figure 11. Schematic representation of steric stabilization by adsorption of polymer structures onto metal nanoparticles in solution 17

Figure 12. (A) the stabilization of each nanoparticles by one polymer chain; (B) the stabilization of many nanoparticles by one poylmer chain ............................................... 18

Figure 13. Representation of the electrosteric stabilization of nanoparticles in solution ..... 18

Figure 14. The experimental setup that used in performing the catalytic hydrolysis of hydrazine borane and measuring the hydrogen generation rate.......................................... 20

Figure 15. UV-Vis spectra of nickel(II) chloride and PSSA stabilized nickel(0) nanoparticles taken from the $10 \mathrm{~mL}$ solution of $1.5 \mathrm{mM} \mathrm{NiCl}_{2}$ and $250 \mathrm{mM} \mathrm{N}_{2} \mathrm{H}_{4} \mathrm{BH}_{3}$ at $25.0 \pm 0.1^{\circ} \mathrm{C}$.

Figure 16. Powder $X$-Ray difraction patterns of in-situ generated PSSMA stabilized nickel(0) nanoparticles isolated from the $10 \mathrm{~mL}$ solution of $5 \mathrm{mM} \mathrm{NiCl}_{2}$ and $300 \mathrm{mM}$

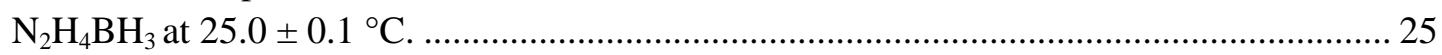

Figure 17. TEM images of PSSMA stabilized nickel(0) nanoparticles $(A, B)$, the corresponding particle size histogram (C), TEM/EDX spectrum of PSSMA-Ni (D) (Nanoparticles were isolated from the $10 \mathrm{~mL}$ solution of $5 \mathrm{mM} \mathrm{NiCl}{ }_{2}$ and $300 \mathrm{mM}$

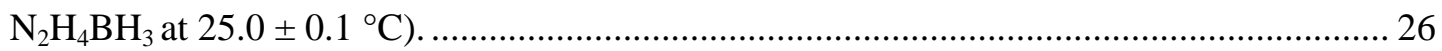

Figure 18. (A) X-ray photoelectron survey scan of PSSMA-stabilized nickel(0) nanoparticles, (B) XPS spectrum of PSSMA-stabilized nickel(0) nanoparticles formed from the reduction of nickel(II) chloride.

Figure 19. Plot of [HB] loss vs time for hydrolysis of HB starting with solution of $300 \mathrm{mM}$ $\mathrm{HB}$ and $4 \mathrm{mM} \mathrm{NiCl}_{2}$ at $25 \pm 0.5{ }^{\circ} \mathrm{C}$. The sigmoidal curve fits to the two-step mechanism for nickel(0) nanoparticle formation

Figure 20. Plots of $\mathrm{mol} \mathrm{H}_{2} / \mathrm{mol} \mathrm{HB}$ versus time depending on the different [PSSMA]/[Ni] ratios for the catalytic hydrolysis of $\mathrm{HB}$. 30

Figure 21. (A) Plot of $\mathrm{mol} \mathrm{H}_{2} / \mathrm{mol} \mathrm{HB}$ versus time (min) for the catalytic hydrolysis of 10 $\mathrm{mL}$ of $300 \mathrm{mM} \mathrm{HB}$ starting with $\mathrm{NiCl}_{2}$ with different nickel concentrations ([Ni] = 2, 2.5, 3, 
4 and $5 \mathrm{mM}$ ) at $25.0 \pm 0.1{ }^{\circ} \mathrm{C}$, (B) plot of the hydrogen generation rate versus the catalyst concentration, both in logarithmic scale, for the catalytic hydrolysis of $\mathrm{N}_{2} \mathrm{H}_{4} \mathrm{BH}_{3} \ldots \ldots \ldots \ldots . . . . . .32$ Figure 22. (A) Plot of $\mathrm{mol} \mathrm{H}_{2}$ / mol HB versus time (min) for the catalytic hydrolysis of $\mathrm{HB}$ starting with $\mathrm{NiCl}_{2}$ precatalyst ([Ni] $=3.0 \mathrm{mM}$ in $10 \mathrm{~mL}$ water), with different $\mathrm{HB}$ concentrations $\left(\left[\mathrm{N}_{2} \mathrm{H}_{4} \mathrm{BH}_{3}\right]=250,300,350,400,500,700\right.$ and $\left.1000 \mathrm{mM}\right)$ at $25.0 \pm 0.1{ }^{\circ} \mathrm{C}$. (B) plot of the hydrogen generation rate versus the substrate concentration, both in logarithmic scale, for the catalytic hydrolysis of $\mathrm{HB}$ starting with $\mathrm{NiCl}_{2}$ precatalyst.............33 Figure 23. Plot of volume of hydrogen $(\mathrm{mL})$ versus time $(\mathrm{min})$ for the catalytic hydrolysis of $\mathrm{HB}\left(\left[\mathrm{N}_{2} \mathrm{H}_{4} \mathrm{BH}_{3}\right]=300 \mathrm{mM}\right.$ in $10 \mathrm{~mL}$ solution) starting with $\mathrm{NiCl}_{2}([\mathrm{Ni}]=3 \mathrm{mM})$ at different temperatures 20, 25, 30, 35 and $40^{\circ} \mathrm{C}$ 35

Figure 24. (A) Arrhenius plot, (B) Eyring plot for the hydrolysis of hydrazine borane $\left(\left[\mathrm{N}_{2} \mathrm{H}_{4} \mathrm{BH}_{3}\right]=300 \mathrm{mM}\right.$ in $10 \mathrm{~mL}$ solution) starting with $\mathrm{NiCl}_{2}([\mathrm{Ni}]=3 \mathrm{mM})$ at $20,25,30$, $35,40{ }^{\circ} \mathrm{C}$ .36

Figure 25. Plot of total turnover number (TTO) versus time for the hydrolysis of hydrazine borane $\left(\mathrm{N}_{2} \mathrm{H}_{4} \mathrm{BH}_{3}\right)$ with a $10 \mathrm{~mL}$ solution of $1.5 \mathrm{mM} \mathrm{NiCl}_{2}$ and $250 \mathrm{mM}$ (for each run) $\mathrm{N}_{2} \mathrm{H}_{4} \mathrm{BH}_{3}$ at $25.0 \pm 0.1^{\circ} \mathrm{C}$.

Figure 26. The mol $\mathrm{H}_{2}$ /mol $\mathrm{HB}$ versus time (min) plot for the hydrolysis of hydrazine borane $(300 \mathrm{mM})$ catalyzed by PSSMAstabilized nickel(0) nanoparticles (4 $\mathrm{mM} \mathrm{Ni})$ with and without addition of 0.2 equiv. $\mathrm{CS}_{2}$ at $25.0 \pm 0.5^{\circ} \mathrm{C}$. 39 


\section{LIST OF ABBREVIATIONS}

$\begin{array}{ll}\text { NPs } & : \text { Nanoparticles } \\ \text { PSSMA } & : \text { Poly(4-styrene sulfonicacid-co-maleic acid) } \\ \mathrm{HB} & : \text { Hydrazine Borane } \\ \mathrm{AB} & : \text { Ammonia Borane } \\ \mathrm{TOF} & : \text { Turnover Frequency } \\ \mathrm{TTON} & : \text { Total Turnover Number } \\ v & : \text { Rate of Reaction } \\ \mathrm{Ea}^{\text {app }} & : \text { Apparent Activation Energy } \\ \Delta \mathrm{H}^{\#, \text { app }} & : \text { Apparent Enthalpy of Activation } \\ \Delta \mathrm{S}^{\#, \text { app }} & : \text { Apparent Entropy of Activation } \\ k_{a p p} & : \text { Apparent Rate Constant }\end{array}$




\section{CHAPTER 1}

\section{INTRODUCTION}

\subsection{Hydrogen As Energy Carrier}

As a result of increasing population and rising living standards the consumption of global energy ceaselessly increases all around the world. Energy sources are used mainly for transportarion sector, in industrial applications, residential and commercial usage and finally for electric power. U.S Energy Information Administration (EIA) reported primary energy consumption by source and sector (Figure 1) [1].

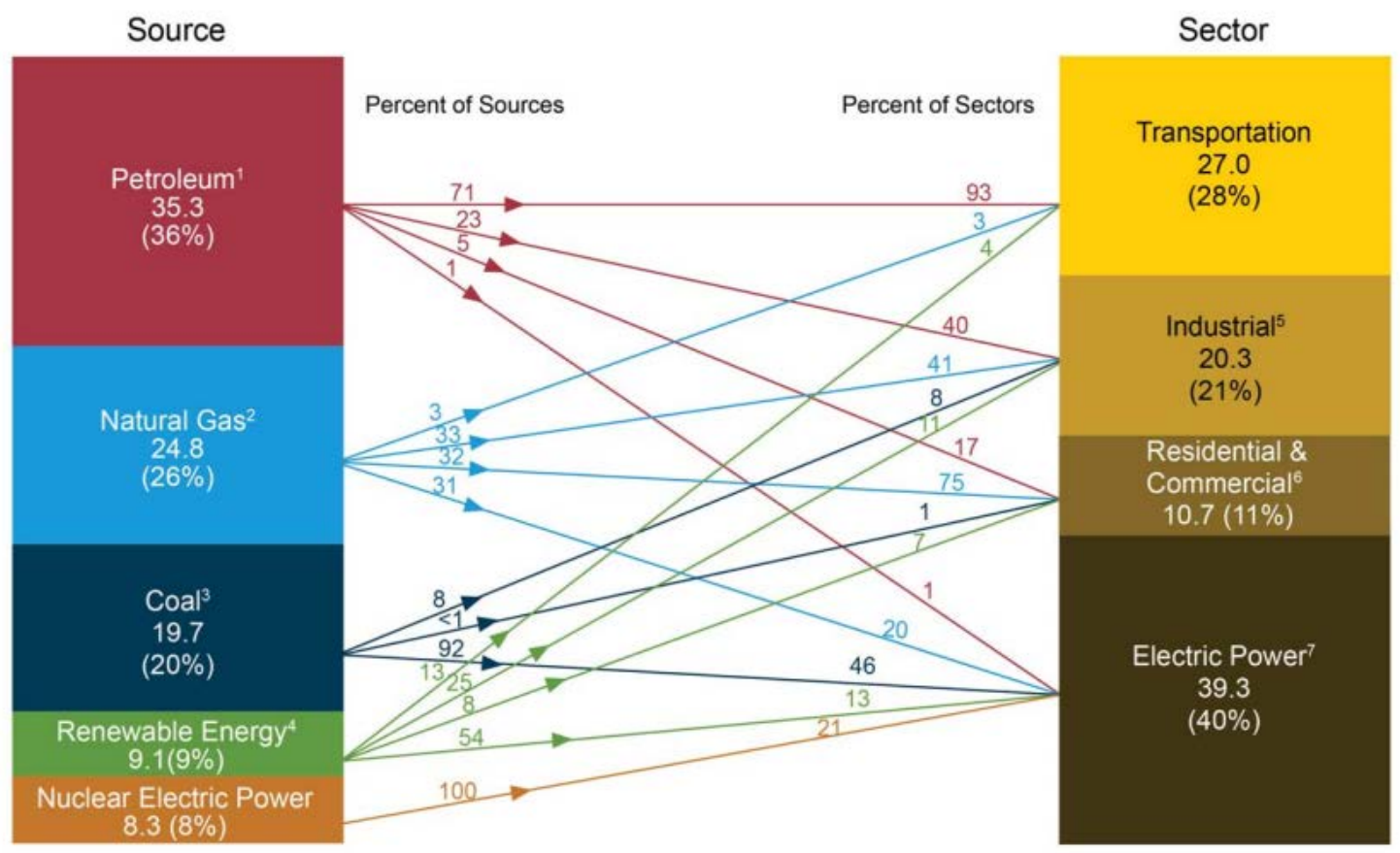

Figure 1- Primary Energy Consumption by Source and Sector [1].

As seen from the Figure, petroleum, natural gas and coal play important role as energy sources with their relatively high percentage. Usage of them causes diminishing of energy resources, many negative effects on global climate and environmental problems [2]. This was supported in 2008 by a special report on renewable energy sources and climate change mitigation, emphasizing that the current global energy system is dominated by fossil fuels [3]. Greenhouse gas emissions coming from the combustion of fossil fuels cause global warming. Because of increasing concern about environmental problems, there has been an important advancement for the renewable energy sources like solar and geothermal energy, wind power, biomass and hydro-electric power. Therefore, renewable energy production has 
been increasing rapidly in recent years. In 2011, EIA indicated $9 \%$ of the primary energy supply composed of renewable energy (Figure 2). In addition, according to Annual Energy Outlook 2012 (AEO 2012), it is also expected that the percentage of renewable energy would be around $14 \%$ of total primary energy supply in the year of 2035 [4].

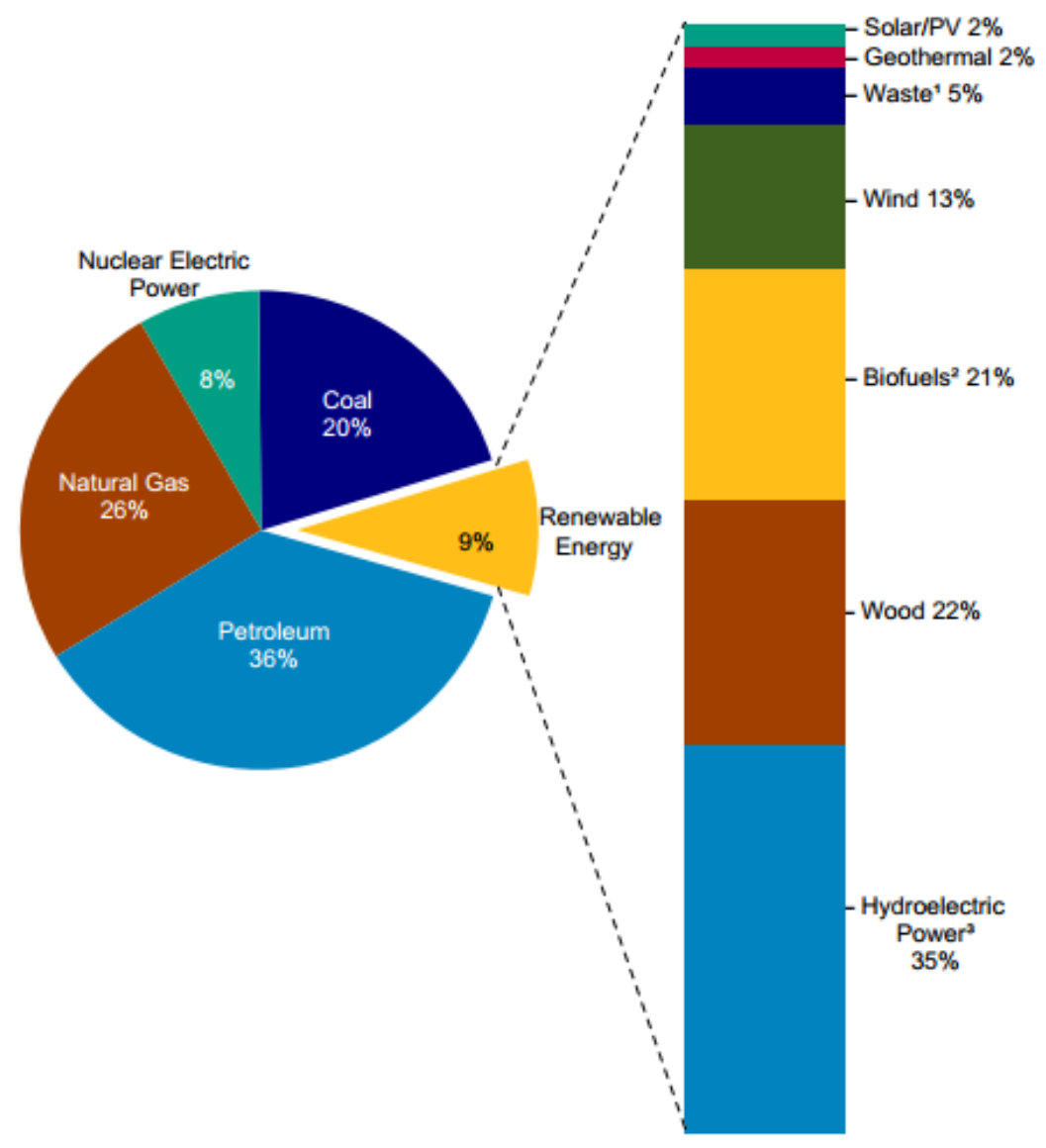

Figure 2. Renewable Energy as Share of Total Primary Energy Consumption [1].

Using renewable energy source is decreasing waste products such as carbon dioxide or other chemical pollutants, so it has minimal impact on the global environment. It is easy to understand environmental advantage of renewables but these kinds of energy forms have also some drawbacks. The major disadvantage for renewable energy sources is reliability of supply. Therefore, there would be a discontinuity problem. Moreover, the energy production from the renewable energy sources requires high cost technologies due to construction of plants and also has low efficiency. The storage of energy would be a solution for this dilemma. From this point of view, hydrogen appears to be the most promising energy carrier which would facilitate the transition from fossil fuels to the renewable energy sources, on the way towards a sustainable energy future [5,6]. Although, hydrogen is the most abundant element in the universe, it does not exist in its elemental form on the Earth. Hydrogen can be 
produced from a wide variety of domestic resources and can be used to provide all energy service needs (Figure 3).

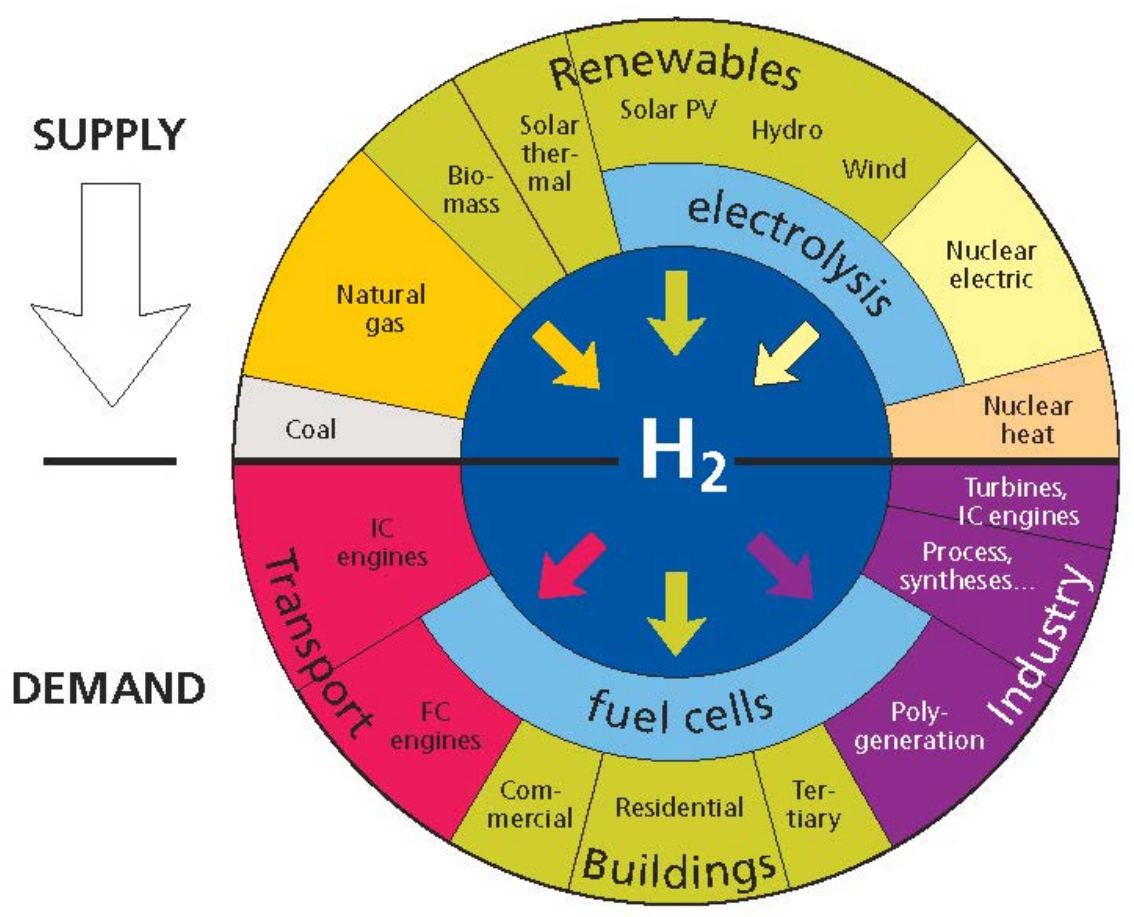

Figure 3. Hydrogen: Promissing Energy Carrier [7]

Furthermore, it is abundant, clean, widely available and highly efficient [8]. Since hydrogen can be produced from a variety of sources, hydrogen is accepted as a promising energy carrier like electricity and can be used in many applications with zero/near zero emissions of green house gases. Therefore, it seems to be the best solution for the present energy problems [9]. Although, it has a very low energy content by volume (8 $\mathrm{MJ} / \mathrm{L}$ for liquid hydrogen versus $32 \mathrm{MJ} / \mathrm{L}$ for gasoline) [10], containing the highest energy content per unit of weight (120 MJ/kg for hydrogen versus $44 \mathrm{MJ} / \mathrm{kg}$ for gasoline) makes it very important opportunity to store it in large quantities [11]. This opinion provided development and improvement of "hydrogen economy". By this way hydrogen can be used as a major carrier in the energy supply cycle. However, light, safe, and compact storage of hydrogen is still a challenge in its implementation [12,13,14]. 


\subsection{Hydrogen Storage}

Hydrogen economy is proposed to remove the negative effects of ; (i) using fossil fuels where the carbon is released to the atmosphere and (ii) renewable energy sources which have low efficiency and high cost. Hydrogen can be produced by using different hydrogen storage technologies. Hydrogen storage is a key point for facilitating technology for the improvement of hydrogen economy. It is very important for fuel cell and hydrogen power technologies, especially, in area of transportation, stationary and portable applications. At the same time, storage of hydrogen is also one of the big challenges to improve hydrogen based technologies. Hydrogen can be stored using either physical storage or material based storage technologies $[15,16]$. The main technologies that developed to store and release pure hydrogen includes: cryogenic liquid [17,18], compressed gas [19,20], adsorption on carbon materials [21,22,23], metal hydrides [24,25] and chemical hydrides [26,27]. High-pressure and cryogenic hydrogen storage systems are impractical for mobile applications due to their safety concerns, cost and volumetric constraints. Reversible hydrogen storage system, like adsorption on simple metal hydrides, can provide 6-9 wt \% of gravimetric storage capacity which is proper for fuel cell applications [28]. However, especially for transportation applications, hydrogen storage requires high volumetric and gravimetric storage capacity. In this content, the 2015 gravimetric storage target of U.S. Department of Energy is $9 \mathrm{wt} \%$ of hydrogen for a chemical storage material [29]. Recently, there is a tremendous interest in developing gravimetrically efficient hydrogen storage materials. Taking into account all these concerns; material based hydrogen storage technologies are being investigated. Among the hydrogen storage materials, chemical hydrides (ammonia borane, hydrides of light elements, etc.) have been considered as hydrogen sources (Figure 4) due to their high hydrogen contents especially for on-board mobile applications at ambient conditios [30,31]. 


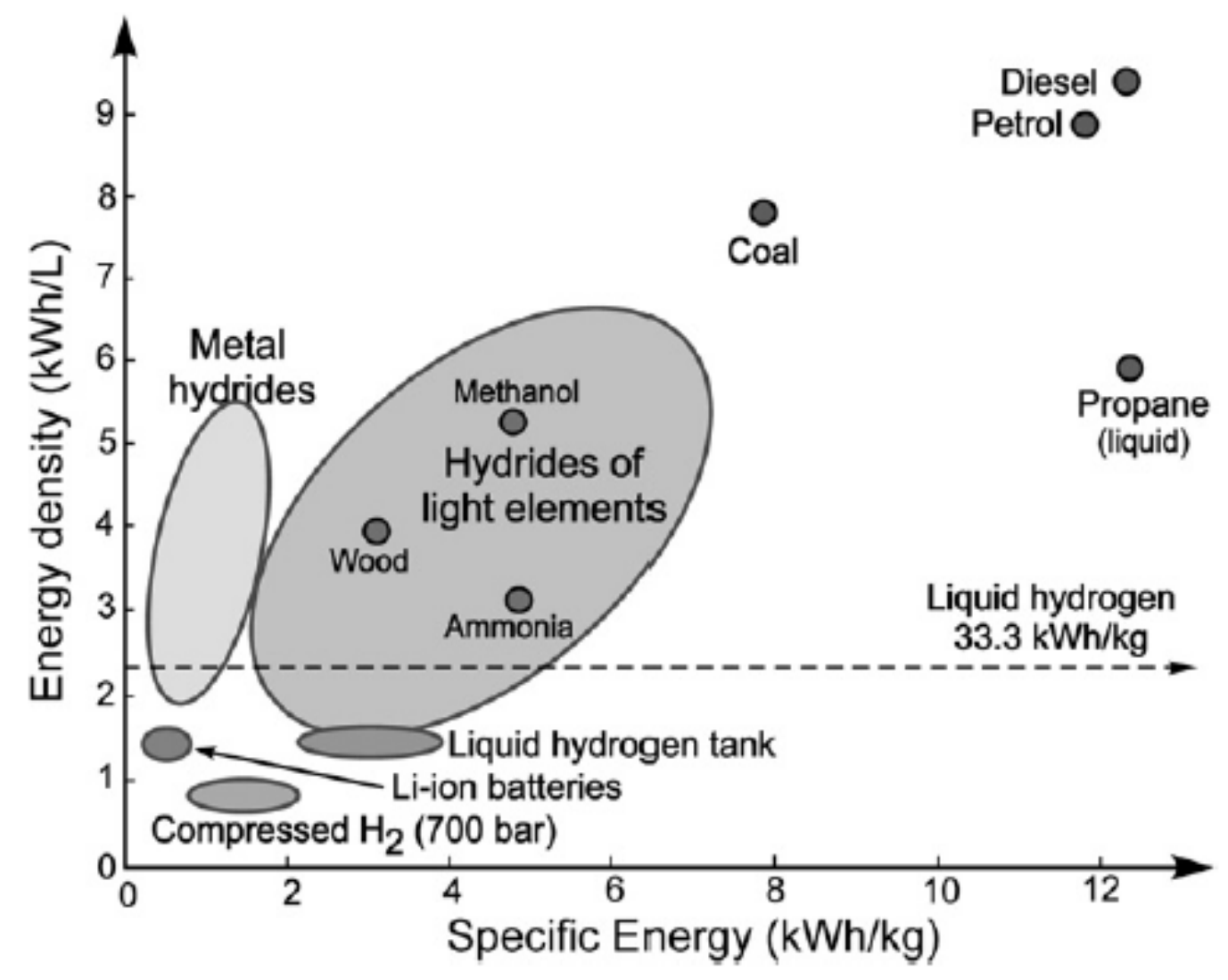

Figure 4. Volumetric and gravimetric energy densities of various energy storage materials [30].

Many chemical hydrides have been tested as solid hydrogen storage materials for onboard applications [32,33,34,35]. In the early 2000s, sodium borohydride was considered as an enterprising hydrogen storage material due to high gravimetric storage capacity (10.3 wt \%) and safety concerns. The first papers dealing with a safe, portable hydrogen gas generator using aqueous borohydride solution were published by Amendola et al. [36,37,38]. Then, the interest to the $\mathrm{NaBH}_{4}$ increased sharply up to "no-go for $\mathrm{NaBH}_{4}$ for on-board automotive hydrogen storage" recommendation of U.S. Department of Energy (US DOE), reporting that the storage technology considered for the hydrolysis of sodium borohydride does not meet the target of 2007 and there is no promising path to reach all of the 2010 targets [39]. After that, many scientists decided to find and study other alternative chemical hydrogen storage materials. Among the several chemical hydrogen storage materials, recently, B-N adducts such as ammonia-borane [40] and hydrazine-borane [41,42,43] have been studied as solid hydrogen storage materials which can be considered as alternative chemicals to the sodium borohydride because of their high content of hydrogen with multiple nature; the protic $\mathrm{N}-\mathrm{H}$ and hydridic $\mathrm{B}-\mathrm{H}$ hydrogen [44]. For on-board hydrogen storage applications, the simplest $\mathrm{B}-\mathrm{N}$ compound ammonia borane $\left(\mathrm{H}_{3} \mathrm{NBH}_{3}, \mathrm{AB}\right)$ is considered to be the most promising candidate due to its noticable gravimetric hydrogen content of 
19.6 wt \% and stability in both solid state and solution under ambient conditions [45,46,47]. It is also one of the accepted chemicals to meet many of the criteria set by the U.S DOE for automotive applications [48]. Releasing of hydrogen stored in $\mathrm{AB}$ can be achieved through mainly two ways; thermolysis and solvolysis $[49,50]$. The hydrolytic dehydrogenation of $A B$ seems to be the most promising way [51,52,53] for on-board applications owing to controlled kinetics of the solvolysis and high temperature requirement of thermolysis $[54,55]$. Nevertheless, its dehydrogenation is incomplete by the fact that the $\mathrm{NH}_{3}$ moiety cannot be decomposed under the hydrolysis conditions [56]. Even, $\mathrm{NH}_{3}$ can be found in the $\mathrm{H}_{2}$ stream when working in high substrate concentrations [57] which is a poison for the catalyst in fuel cell applications. This problem can be solved by using hydrazine borane $\left(\mathrm{H}_{2} \mathrm{NNH}_{2} \mathrm{BH}_{3}, \mathrm{HB}\right)$ as another promising hydrogen storage material [58].

\subsection{Hydrazine Borane and Its Hydrolysis Reaction}

Hydrazine borane $\mathrm{H}_{2} \mathrm{NNH}_{2} \mathrm{BH}_{3}$ (HB) is one of the promising candidates for hydrogen storage materials because of its low molecular weight $(45.8 \mathrm{~g} / \mathrm{mol})$ and high hydrogen content ( 15.4 wt $\% \mathrm{H}_{2}$ ). There are two types of hydrogen that can be released. Four of them are protic $\left(\mathrm{N}-\mathrm{H}, \mathrm{H}^{\delta+}\right)$ and three of them are hydridic $\left(\mathrm{B}-\mathrm{H}, \mathrm{H}^{\delta-}\right)$ come from $\mathrm{N}_{2} \mathrm{H}_{4}$ group and $\mathrm{BH}_{3}$ group, respectively. Hydrazine borane is easily prepared from a reaction of dihydrazine sulfate and sodium borohydride (eqn (1)) [59].

$$
2 \mathrm{~N}_{2} \mathrm{H}_{4} \cdot \frac{1}{2} \mathrm{H}_{2} \mathrm{SO}_{4}(s)+2 \mathrm{NaBH}_{4}(s) \stackrel{T H F, R T}{\longrightarrow} 2 \mathrm{~N}_{2} \mathrm{H}_{4} \mathrm{BH}_{3}(s)+\mathrm{Na}_{2} \mathrm{SO}_{4}(s)+2 \mathrm{H}_{2}(g)
$$

Hydrogen generation from HB can occur either via thermolysis [41] or hydrolysis [42]. In hydrolysis reaction, generally, 3 moles of hydrogen generation comes through from the hydridic part of HB in the presence of suitable catalyst (eqn (2)).

$$
\mathrm{N}_{2} \mathrm{H}_{4} \mathrm{BH}_{3}(a q)+2 \mathrm{H}_{2} \mathrm{O}(l) \stackrel{\text { catalyst }}{\longrightarrow} \mathrm{N}_{2} \mathrm{H}_{5} \mathrm{BO}_{2}(a q)+3 \mathrm{H}_{2}(g)
$$

In hydrolysis reaction, hydrogen gas is liberated in the presence of metal based catalyst. In literature, generally precious transition metal nanocatalysts (monometallic or bimetallic) were used for catalytic hydrolysis of hydrazine borane [43,60,61]. Recently, Miele and coworkers studied transition metal-catalyzed dehydrogenation of $\mathrm{HB}$ via the hydrolysis of $\mathrm{BH}_{3}$ and the decomposition of $\mathrm{N}_{2} \mathrm{H}_{4}$. In that study, they considered various transition metal salts as precursors of in situ forming catalysts by reduction in the presence of HB. According to activity, they classified the metal catalysts into 3 groups [60];

(i) Fe- and Re- based catalyst: shows limited activity in the hydrolysis of $\mathrm{BH}_{3}$ group.

(ii) Co-,Ni-,Cu-,Pd-,Pt-, and Au- based catalyst: only active in the hydrolysis of $\mathrm{BH}_{3}$ group.

(iii) $\mathrm{Ru}-, \mathrm{Rh}$ - and Ir- based catalyst: active both in the hydrolysis of $\mathrm{BH}_{3}$ and in the decomposition of $\mathrm{N}_{2} \mathrm{H}_{4}$. 
Miele and coworkers also studied using different metal chloride based catalysts for hydrogen generation from HB. They concluded that rhodium metal appears as an attractive catalyst for the hydrolytic dehydrogenation of $\mathrm{N}_{2} \mathrm{H}_{4} \mathrm{BH}_{3}$ [43]. The recent studies have also shown that the extent of hydrogen generation can be increased up to 5 equivalent of $\mathrm{H}_{2}$ via both hydrolysis of the $\mathrm{BH}_{3}$ group and complete decomposition of the $\mathrm{N}_{2} \mathrm{H}_{4}$ group by using bimetallic catalyst like $\mathrm{Ni}_{1-\mathrm{x}}-\mathrm{Pt}_{\mathrm{x}}$ nanocatalysts, which amplifies the importance of the use of hydrazine-borane in the chemical hydrogen storage [61]. Miele and et al. also worked on nickel based bimetallic nanocatalyst containing ruthenium, rhodium, platinum or iridium as second metal. The best performances were achived with $\mathrm{Ni}_{0.89} \mathrm{Rh}_{0.11}$ and $\mathrm{Ni}_{0.89} \mathrm{Ir}_{0.11}$ catalysts [43].

In literature, the hydrolysis of $\mathrm{BH}_{3}$ group has fast kinetics compared to the dehydrogenation of $\mathrm{N}_{2} \mathrm{H}_{4}$ group [60]. By using bimetallic catalyst both hydrolysis of $\mathrm{BH}_{3}$ group and dehydrogenation of the $\mathrm{H}_{2} \mathrm{NNH}_{2}$ have been investigated in a two-step process [43]. The decomposition and/or dehydrogenation of the $\mathrm{H}_{2} \mathrm{NNH}_{2}$ moiety has slow kinetics and could not occur at room temperature, it needs higher temperature values. Therefore, it would not be convenient to generate hydrogen from both of these groups due to different reaction kinetics of two-step reactions. Especially for fuel cell applications, slow reaction kinetics and requirement of high temperature for decomposition of $\mathrm{N}_{2} \mathrm{H}_{4}$ moiety may not be preferable.

In addition to the reaction conditions and kinetics, there is another issue that should be considered for hydrolysis of $\mathrm{HB}$, which is stability of catalyst. Transition metal(0) nanoparticles can be stabilized in a certain extent against the aggregation into bulk metal. There have been many articles about the mode of stabilization of nanoparticles reported in literature [62,63]. The stabilization of metal nanoparticles can be provided by using proper stabilizers like electrostatic, steric and electrosteric stabilizers $[98,113]$. There are several metal catalysts for hydrogen generation from HB [43,60,61]. In these studies, there were no stabilization agents used to prevent aggregation; as a result, enough stabilization of catalyst could not be provided against aggregation. Therefore, it is reported that the black solids formed by reduction of platinum(II) and rhodium(III) by HB and aggregated nanoparticles of platinum(0) and rhodium(0) were observed [42,60].

Water soluble polymers are the most widely used steric stabilizers for the preparation of stable metal nanoclusters in solution. For this reason, in this dissertation, one of the most widely used water soluble polymer, poly(4-styrenesulfonic acid-co-maleic acid) (PSSMA) (Figure 5), was used to provide stabilization of nickel(0) nanoparticles. Then, PSSMA stabilized nickel(0) nanoparticles were used as catalyst in hydrogen generation from the hydrolysis of HB. This is the first study for hydrolysis of HB in the presence of PSSMA stabilized nickel(0) nanoparticles. 


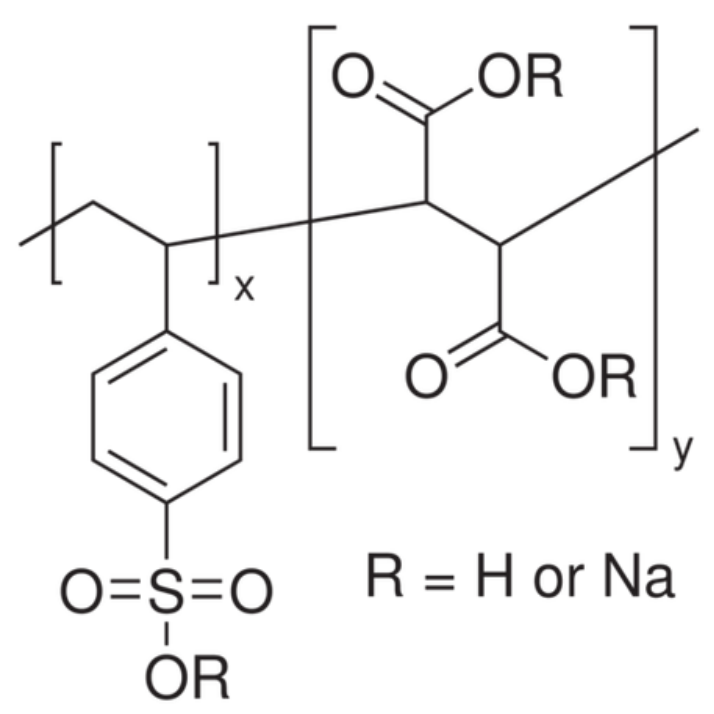

Figure 5. The structure of poly(4-styrenesulfonic acid-co-maleic acid)

There is one more point of view which also supports this dissertation in terms of usage of HB instead of ammonia borane (AB) as hydrogen storage material. The previous study [64] about the hydrolysis of AB in the presence of PSSMA stabilized nickel(II) chloride reported that the usage of sodium borohydride was found to be necessary for the reduction of metal ion to its metallic state. Because, it was concluded that no reduction and hydrogen generation were observed by performing the catalytic hydrolysis reaction only in the presence of AB. On the other hand, in this study, hydrazine borane was found as an efficient substrate to reduce metal ions to their metallic state in all experiments. Therefore, there is no need to use any reducing agent like sodium borohydride. The usage of $\mathrm{NaBH} 4$ as a reducing agent results in additional hydrogen gas coming from its hydrolysis [64,65]. Although limited amount of sodium borohydride is used; it behaves as second hydrogen source which can cause confusion about the source of generated hydrogen. 


\subsection{The Motivation of the Dissertation}

As mentioned in the previous section, hydrogen is promising energy carrier; however, light, safe, and compact storage of hydrogen is still a challenge in its implementation. Consequently, there has been an extensive motivation in searching for chemical materials possessing high gravimetric hydrogen density suitable for both portable and stationary applications. For this purpose, in this dissertation hydrogen generation was studied by using hydrazine borane as a hydrogen storage material and catalytic hydrolysis reaction was preferred to generate hydrogen from this substrate. As catalyst, transition metal(0) nanoparticles were decided to be used. In order to provide stable nanoparticles in solution with controllable size, polymer chains were used as one of the strong steric stabilizer.

Herein, we report in-situ preparation and characterization of poly(4-styrenesulfonic acid-co-maleic acid) (PSSMA) stabilized nickel(0) nanoparticles and catalytic activity investigation and kinetic studies of them in the hydrogen generation from the hydrolysis of HB. Nickel(0) nanoparticles, formed from the reduction of nickel(II) chloride during the hydrolysis of HB in the presence of PSSMA, were isolated from the reaction solution by centrifugation and characterized by XRD, XPS, TEM, EDX and UV-vis electronic absorption spectroscopy. Nickel(0) nanoparticles of the size of $8.3 \pm 2.3 \mathrm{~nm}$ stabilized by PSSMA were found to be highly active catalyst providing 1600 turnovers in hydrogen generation from the hydrolysis of hydrazine-borane at room temperature. The work reported here also includes (i) the collection of wealthy kinetic data to demonstrate the effect of substrate and catalyst concentrations on the hydrogen generation rate and to determine the rate law for the catalytic hydrolysis of hydrazine-borane, (ii) the investigation of the effect of temperature on the rate of hydrogen generation and determination of activation parameters for the catalytic hydrolysis of hydrazine-borane. 


\section{CHAPTER 2}

\section{CATALYSIS AND TRANSITION METAL(0) NANOPARTICLES}

\subsection{Catalysis}

Catalysis is about reaction kinetics, not reaction thermodynamics. It deals with changes on the route to equilibrium. Therefore, catalysts do not change the thermodynamic equilibrium. The reaction thermodynamics define destination of an extent of process from the starting point to the end of reaction. However, the reaction kinetics only related with which pathway has been taken by process [66]. This phenemona is very important through the selection of suitable catalyst in order to make it applicable for desired reaction process. During the catalytic operation, the catalyst is not consumed and each molecule can participate in many sequencial cycles. Therefore, it is proper to use only a small amount of catalyst relative to substrate. The classification of catalysis can be made under three main headings; (I) heterogeneous catalyst, (II) homogeneous catalyst and (III) biocatalyst as shown in Figure 6.

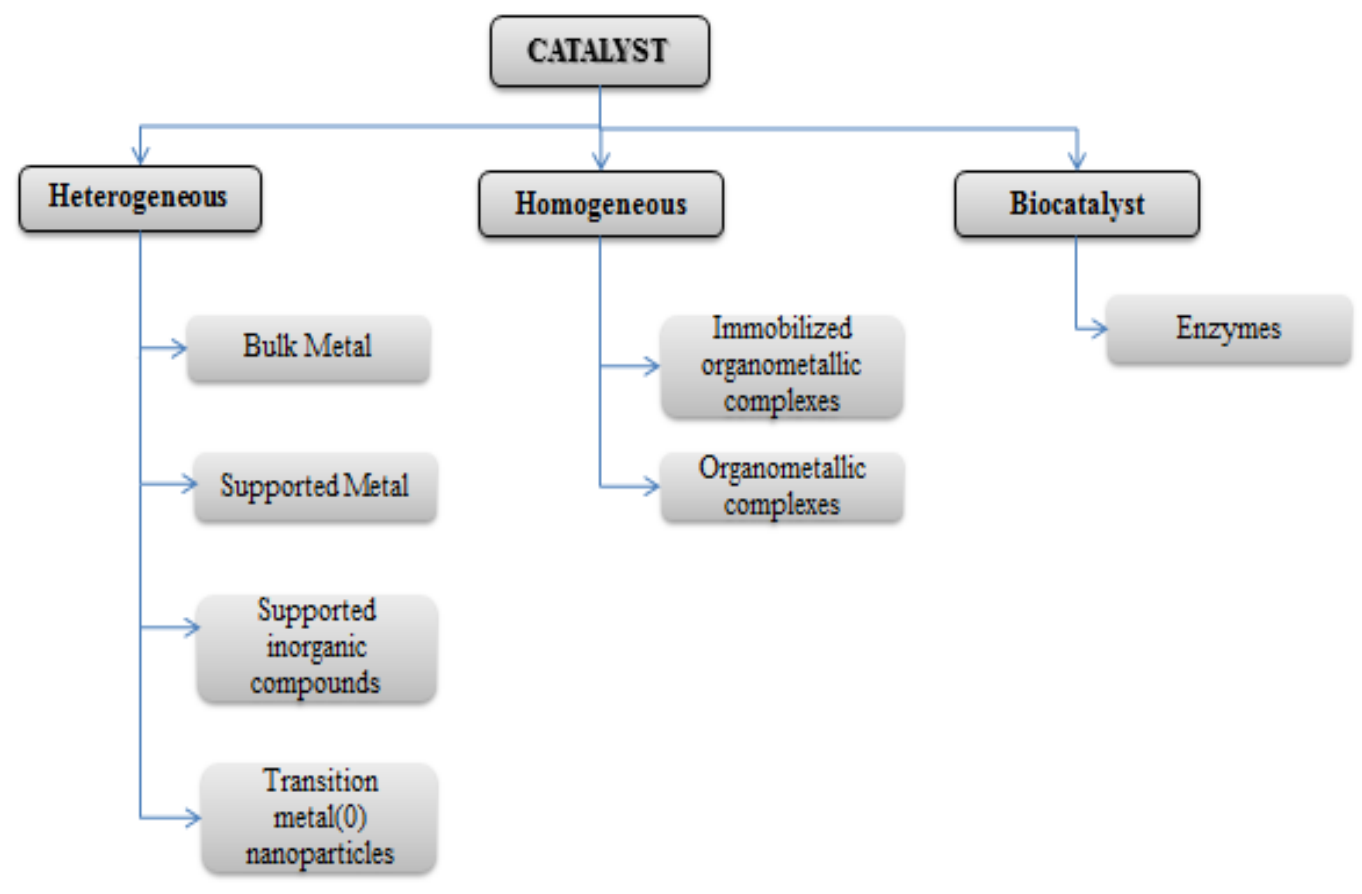

Figure 6. The classification of catalysts [67]. 
The assortment of homogeneous and heterogeneous catalysis depends on existence of catalyst in the same phase as the substrate or not. In the case of homogeneous catalysis, the catalyst is in the same phase as the reactants and the products and the catalyst and substrate are reacted in a solvent. On the other hand, in heterogeneous catalysis, the catalyst and the reactants are in different phases. They are generally referred as a system in which catalyst is solid. In heterogeneous catalytic systems, catalyst is easily separated from the reaction medium and this makes the heterogeneous catalysis more advantageous. The last group is biocatalysis. It is rather special case, somewhere between homogeneous and heterogeneous catalysis. The biocatalyst is generally a complex protein that catalyzes the reactions in living cells [68]. They are both selective and highly efficient catalyst which can catalyze the 1000 catalytic cycles in one second.

Recent decades, there is a great attraction for development of new and efficient catalyst. An efficient catalyst is required to have capability to produce high yield product with high selectivity. There are mainly two important parameters in order to characterized catalyst; activity and selectivity. To determine activity of a catalyst, the total turn over number (TTON) is calculated. TON means how many times the catalyst converts the starting material to the product during reaction process. The total turn over number can be also defined as the number of mole of product per mole of catalyst (eqn(3)).

$$
\mathrm{TTON}=\frac{\text { mol of product }}{\text { mol of catalyst }}
$$

Turnover frequency (TOF) is another parameter which is used to specify the activity of catalyst is related to turn over number. For the conversion of A to the product B in the presence of catalyst with a rate of $v$, the following relation can be expressed for turnover frequency (eqn (4)).

$$
\begin{gathered}
\mathrm{A} \stackrel{\text { catalyst }}{\longrightarrow} \mathrm{B} \\
v=\frac{d[B]}{d t} \\
\mathrm{TOF}=\frac{v}{\text { catalyst }}
\end{gathered}
$$

The TTON expresses the reliability of the catalyst in the reaction regardless of the reaction rate, on the other hand, TOF reflects kinetic factor that is how fast the catalytic reaction progresses [69]. 
Selectivity is also important parameter that ought to be considered in the evaluation of the performance of any catalyst. It is the ability of catalyst to lead chemical reaction to yield a desired product. Especially for industrial application, selectivity of catalyst play very important role to achieve intended reaction product with minimum amount of side products.

\subsection{Nanoparticles (NPs)}

The $21^{\text {st }}$ century can be named as century of nanotechnology and nanometric catalysis has generated great importance through the technological improvement. They can be used to produce variety of product in many different application areas. Nanometric catalysts can be arranged on nanoscale somewhere between the bulk solid and molecular state (Figure 7). Nanoparticles, which are described as any type of metallic species with a size between 1-25 nm, appear on nanoscale by attracted great attention. They can be used in wide range of area like physics, chemistry, material science, bilogy and medicine.

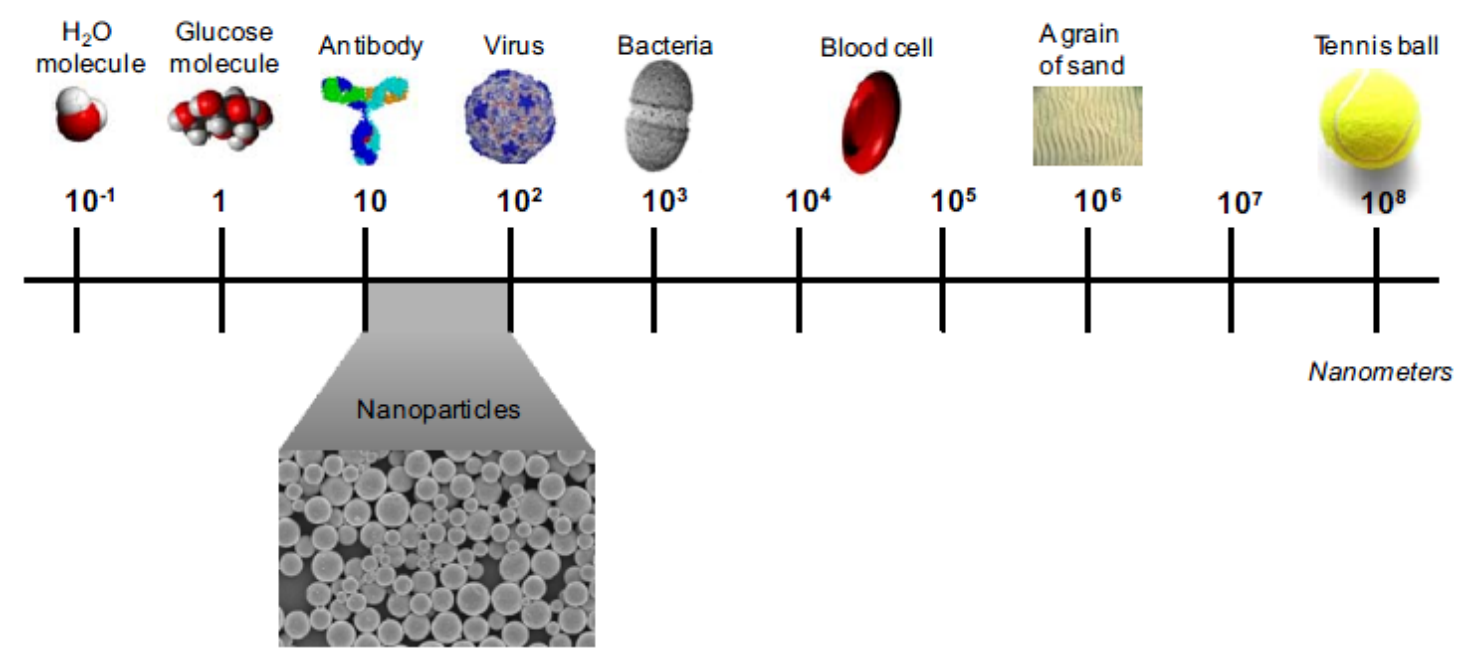

Figure 7. Nanoparticles in the nanoscale pattern [70]

Nanoparticles display quantum size effects due to their dimensions. When the particle size reduced to about $1-10 \mathrm{~nm}$, the nanoparticle would be intermediate between individual atoms or molecule and bulk metal. This property provides unique catalytic activity.

\subsubsection{Transition Metal Nanoparticles: Suitable Catalyst for Hydrogen Generation}

Transition metal nanoparticles are nearly monodispersed particles which are about 1-10 nm (10-100 $\AA)$ in diameter [71]. There is a considerable interest in the synthesis and the usage of transition metal nanoparticles owing to their novel physical and chemical properties [72]. They are widely used in variety of catalytic application fields [73] such as chemical sensors [74], photochemistry [75], nanoelectronics [76], quantum computers [77], and optics [78]. Besides, transition metal nanoparticles have high surface area which 
provides many numbers of potential active sites. Thus, they can find great application areas in chemical reactions as catalysts. This facilitates development of transition metal nanoparticles in the synthesis of many fine chemicals which are environmental and economical [72]. They leap out as catalyst in hydrogen generation from hydrogen storage material with their high activity due to moderately high surface-volume ratio and large number of active atoms which hinge on the surface [79].

Transition metal nanoparticles have a high percentage of surface atoms and they do not necessarily order themselves in the same way that those in bulk do. As an illustrative example Klabunde and co-workers calculated the percentage of surface iron atoms on spherical iron(0) nanoparticles depending on their size (Figure 8).

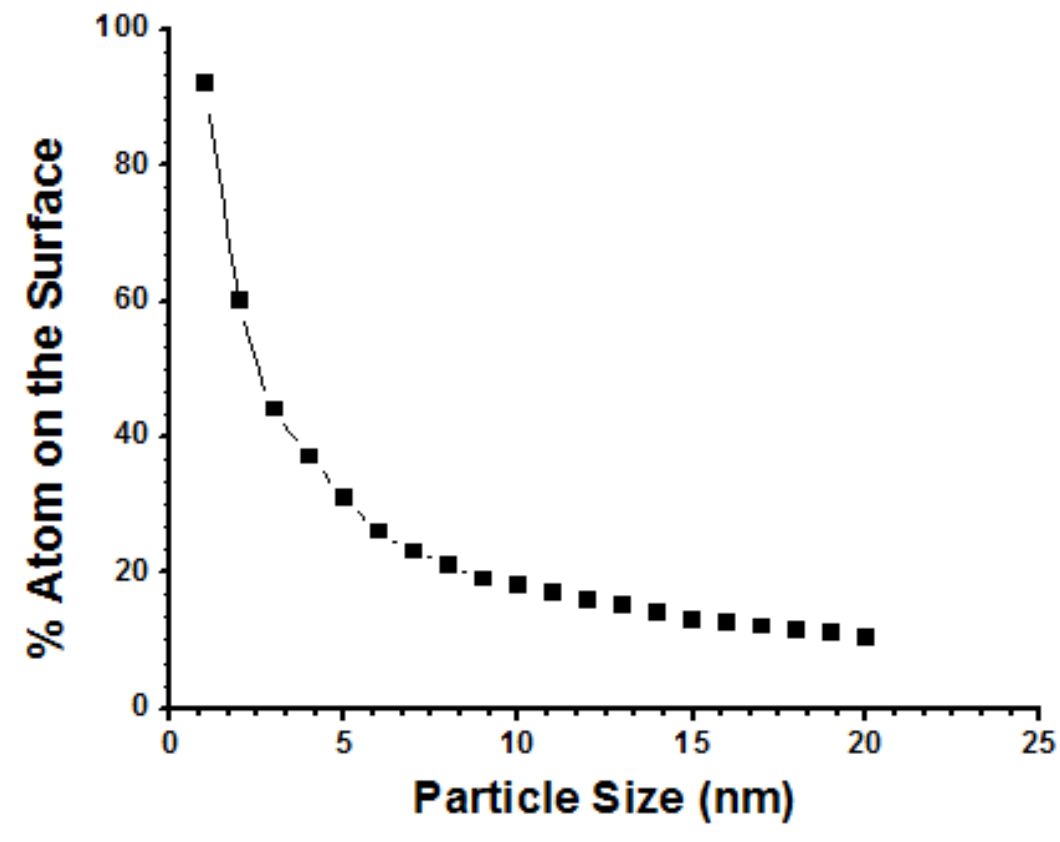

Figure 8. The change in percentage of surface iron atoms depending on the size of iron(0) nanoparticles [80].

When compared with bulk metals, the increasing proportion of surface atoms with decreasing particle size makes transition metal nanoparticles more active catalyst than their bulk compeers.

However, there is a challenge that should be solved to use transition metal NPs as catalyst. Although they are kineticly stable, unfourtunately thermodynamically unstable in solution to agglomerate into bulk metal. Therefore, they tend to be quite unstable against agglomeration or precipitation during synthesis and preparation processes. As a result, size and shape of them should be controlled to provide high activity and selectivity and some 
special precautions have to be taken to prevent their agglomeration or precipitation in solution and to allow stable nanoparticle formation [71,81].

\subsubsection{Synthesis and Stabilization of Transition Metal Nanoparticles}

\subsubsection{Synthesis of Transition Metal Nanoparticles}

For the synthesis of nanomaterials and fabrication of nanostructures there are two basic approaches; "top-down" and "bottom up". Top -down approach bases on principles of microsystem technology which use mechanical-physical particle production processes. The conventional mechanical-physical crushing method uses milling to crush microparticles. However using mills to crush particles cause to yield powders with relatively broad particle size ranges. Therefore, this method does not allow full control of particle shape. On the other hand, bottom-up approaches based on chemo-physical production process which uses principles of molecular or atomic self-organization. By using this method, one can produce selected, more complex nanostructures from atoms or molecules by controlling size, shapes and particle size range [82]. Common bottom up methods are chemical, electrochemical, templating, photochemical, nanosphere lithography and thermal reduction techniques [83]. In general, regarding chemical bottom-up approaches, these techniquies can be categorized into; (I) reduction of transition metal salt precursor [84,85,86,87] (II) electrochemical synthesis [88,89] (III) reduction of organic ligands in organometallic precursors [90], and (IV) reduction of organic ligands in organometallic precursors [91]. In this dissertation, nanoparticles are fabricated by using reduction of transition metal salt precursor through which the nucleation and growth of metallic atoms take place. This approach (eqn (5), Figure 9) involves mixing metal precursor with the reducing agent (e.g.alcohol, hydrazine, dihydrogen, or borohydride) in the presence of stabilizing agents (ligands, polymers, surfactants). Stabilizer used for preventing undesired formation of metal powders [92].

$$
x \mathrm{M}^{+\mathrm{n}}+n x e^{-}+\text {stabilizer } \stackrel{\text { catalyst }}{\longrightarrow} \mathrm{M}_{n(\text { particle })}^{0}
$$

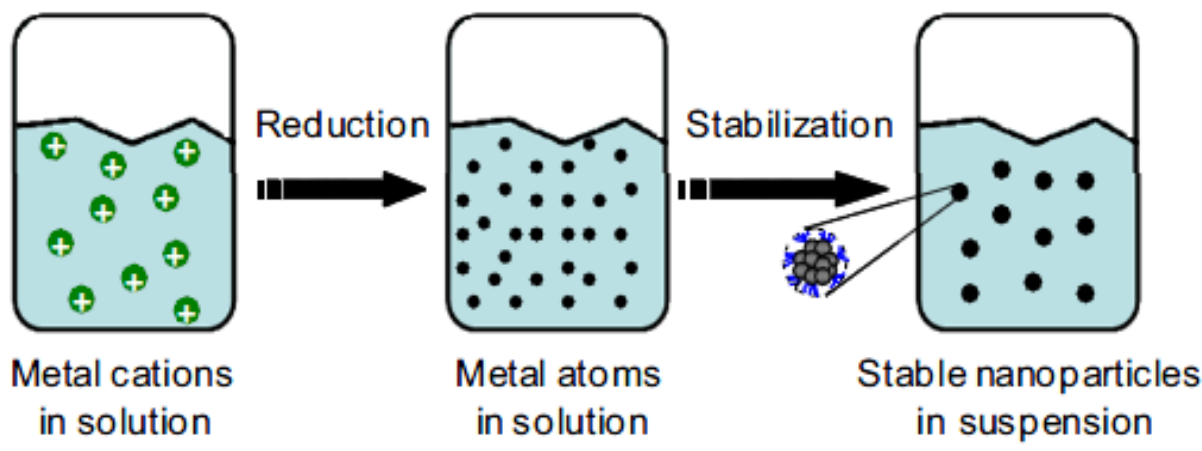

Figure 9. Formation of nanoparticles via reduction of metal salt precursors [92]. 


\subsubsection{Stabilization of Transition Metal Nanoparticles}

Unique properties of transition metal nanoparticles that differ from their bulk counterparts make them promissing candidate to facilitate their application in various field. Their employment in catalysis has provided significant advantages especially in solution. However, metal nanoparticles are thermodynamically unstable in solution to agglomerate into bulk metal. Therefore, all metal nanoparticle preparation methods involve the utilization of stabilizing agents to avoid nanoparticle aggregation or precipitation. In the literature, there are three methods for stabilizing metal NPs; electrostatic, steric and electrosteric stabilization.

\section{(i) Electrostatic Stabilization}

Derjaguin-Landau-Verway-Overbeek (DLVO) theory establishes colloidal stabilization. According to DLVO theory, stability of colloidal system is defined by the sum of Van der Waals attractive forces and electrical double layer repulsive forces [93]. The repulsive electrostatic force is the origin of electrostatic stabilization when nanoparticles are surrounded by a double layer of electric charges. The electrostatic repulsion prevents aggregation when the electrical potential resulting from the double layer is high enough [94] (Figure 10).
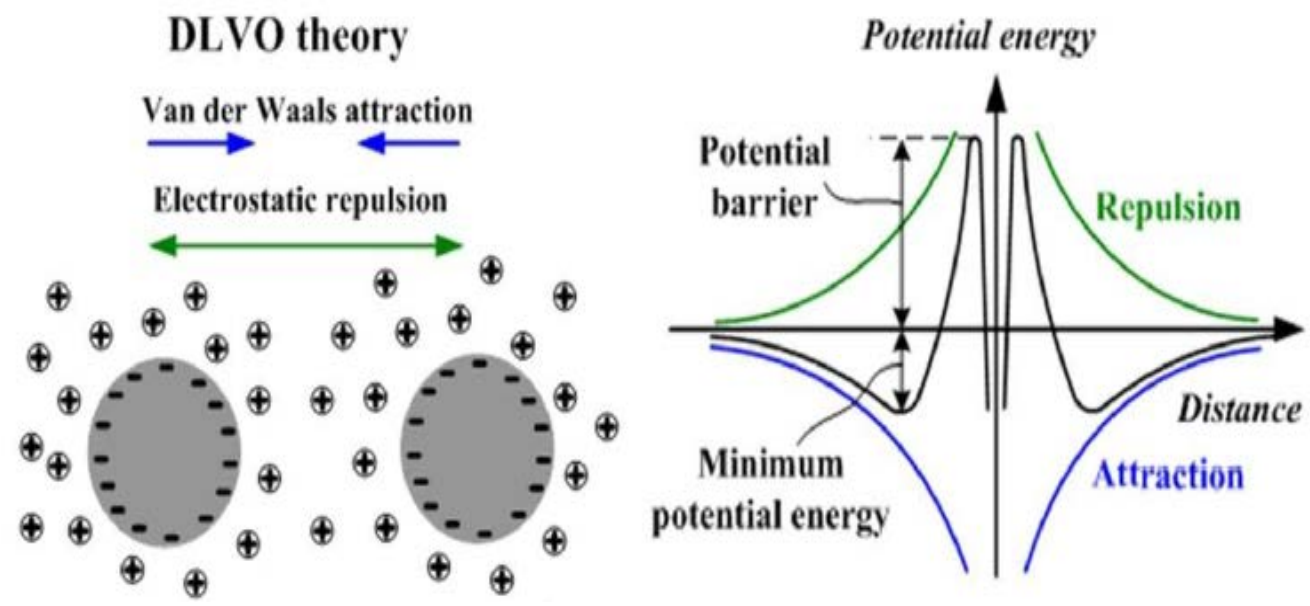

Figure 10. Schematic representation of the electrostatic stabilization of transition metal nanoparticles [95]. 


\section{(ii) Steric Stabilization}

Steric stabilization is a method that is widely used in stabilization of colloidal dispersions [96]. In order to prevent agglomeration; polymeric molecules, surfactants or long chain ligands are added to the dispersion medium to provide a protective layer [97]. These kinds of adsorbates generate steric barrier by creating a repulsive force in order to counterbalance the Van der Waals attractive force which is acting on a particle getting close to another particle. As a result, close contact of metal particle centers is prevented (Figure 11) [98].

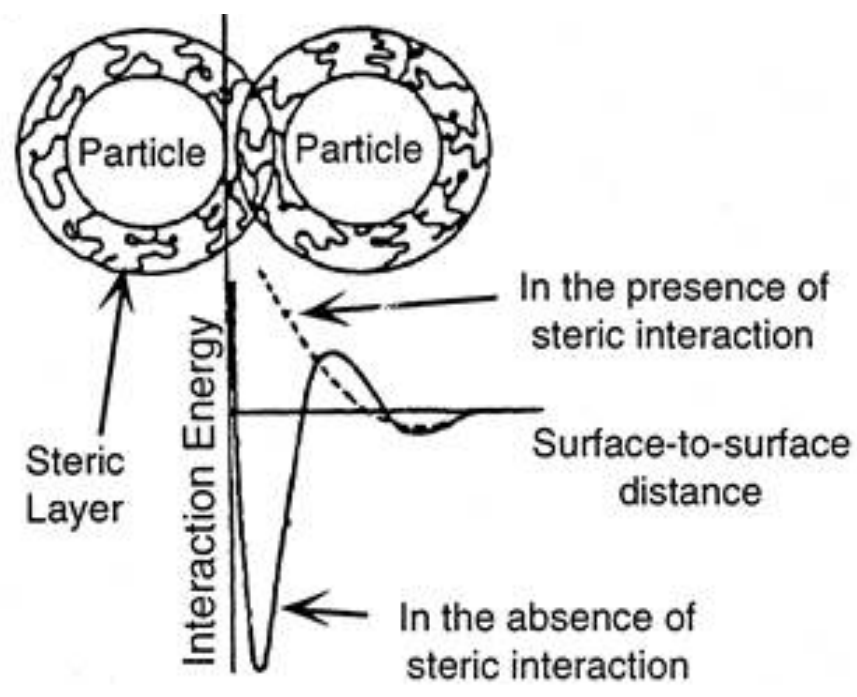

Figure 11. Schematic representation of steric stabilization by adsorption of polymer structures onto metal nanoparticles in solution [98].

In general, polymers are widely used for this purpose that can bind tightly to metal NPs via chemical bonding. They can coordinate to the metal particle at multiple sites. There are mainly two suggested models for nanoparticle stabilization using polymers. The first and ordinarily accepted one is the stabilization of each nanoparticle by one polymer chain (Figure 12A). And the other model is the stabilization of many nanoparticles by one polymer chain (Figure 12B). In heterogeneous catalytic applications, it is important to have a large active metal surface and both of models provide it. 


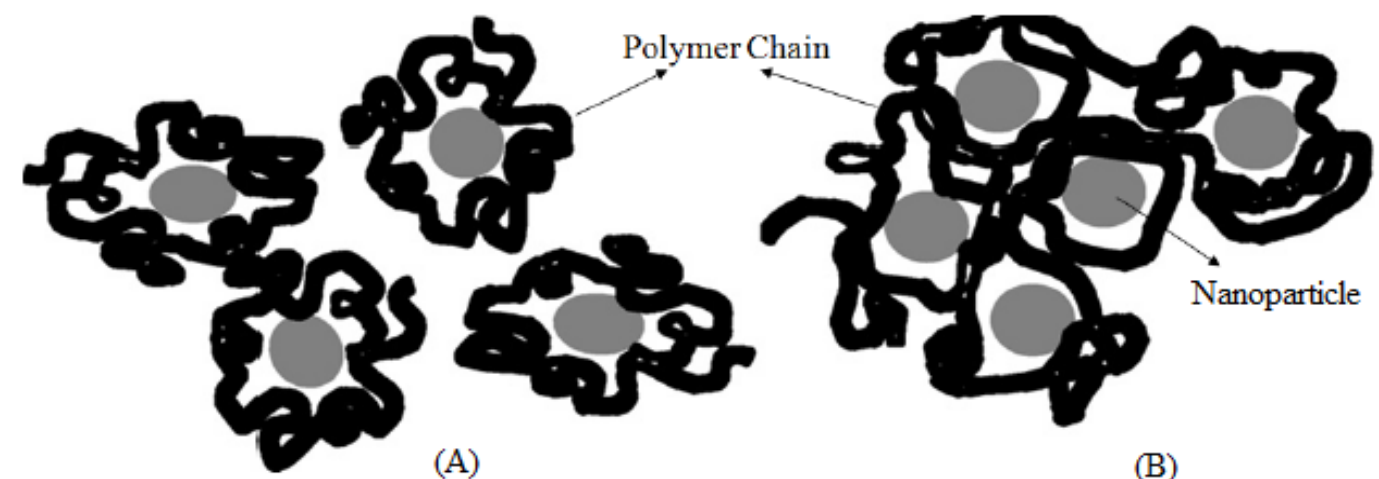

Figure 12.(A) the stabilization of each nanoparticles by one polymer chain; (B) the stabilization of many nanoparticles by one polymer chain [99].

The use of polymeric matrix as stabilizer improves some properties of the nanoparticles such as the solubility, thermal stability and catalytic activity [100].

(iii)

\section{Electrosteric stabilization}

Electrosteric stabilization can be defined as the combination of electrostatic and steric stabilization in order to provide thermodynamically stable nanoparticles in solution [101]. For this purpose, ionic surfactants are generally used. As shown in Figure 13, they can generate a polar head group which can create electrical double layer and a lypophilic side chain which can provide steric repulsion. At the time two particles approach each other, both electrostatic repulsion and steric limitation prevent agglomeration of nanoparticles.

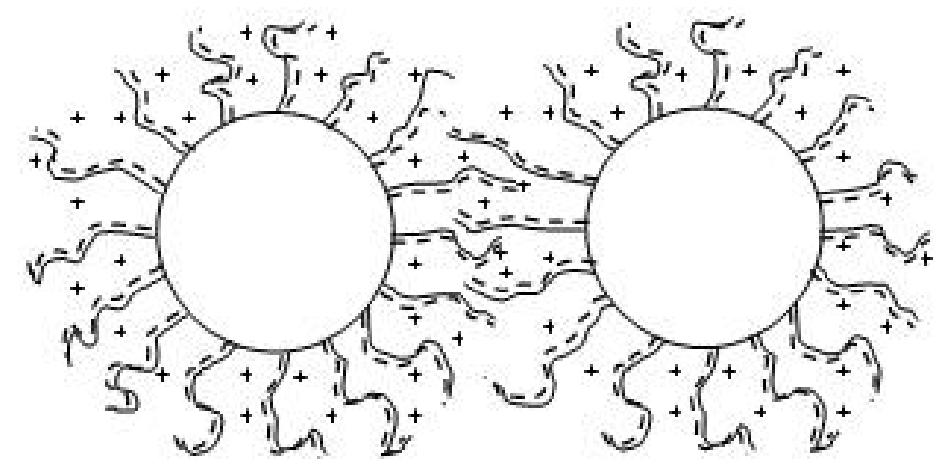

Figure 13. Representation of the electrosteric stabilization of nanoparticles in solution [102]. 


\section{CHAPTER 3}

\section{EXPERIMENTAL}

\subsection{Materials}

Nickel(II) chloride hexahydrate (>99\%) is purchased from Merck, poly (4styrenesulfonic acid-co-maleic acid) sodium salt, sodium borohydride (98\%), tetrahydrofuran (99.9\%) were purchased from Aldrich. Dihydrazine sulfate $\left(\mathrm{N}_{2} \mathrm{H}_{4} \cdot 0.5 \mathrm{H}_{2} \mathrm{SO}_{4}\right)$ (98\%) was purchased from Acros-Organics. Carbon disulfide $\left(\mathrm{CS}_{2}\right)$ was also purchased from Merck. THF was distilled over sodium/benzophenone under argon and stored in the drybox $\left(\mathrm{H}_{2} \mathrm{O}\right.$ and $\left.\mathrm{O}_{2}<1 \mathrm{ppm}\right)$. Deionized water was distilled by water purification system (Milli-Q System). All glassware and Teflon coated magnetic stir bars were cleaned with acetone, followed by copious rinsing with distilled water before drying in an oven at $150{ }^{\circ} \mathrm{C}$.

\subsection{In Situ Formation of PSSMA Stabilized Nickel(0) Nanoparticles and Catalytic Hydrolysis of Hydrazine Borane with Hydrogen Generation Data Handling}

In situ formation of PSSMA stabilized nickel(0) nanoparticles and catalytic hydrolysis of hydrazine borane were performed in the same medium. The jacketed reaction flask (20 mL) which contains a Teflon-coated stir bar was placed on a magnetic stirrer and thermostated to $25 \pm 0.5{ }^{\circ} \mathrm{C}$ by circulating water through its jacket from a constant temperature bath. The mixture of $300 \mathrm{mM}$ HB (138 mg) and $3 \mathrm{mM}$ PSSMA (10.3 mg) was dissolved in $7 \mathrm{~mL}$ water at reaction flask (20 mL). Then, $10 \mathrm{mM}$ of nickel(II) chloride (3mL) was transferred into the reaction flask using gastight syringe and solution was stirred at 1000 rpm. At the beginning of the reaction there was no color change on the reaction medium that was observed. After the reaction was started, about 30 min later the color change from the original metal precursor solution (pale green) to dark brown was observed. This indicates formation of nickel( 0 ) nanoparticles. The time passing until reduction of metal precursor is named as the induction period [103]. Hydrogen gas generation from the catalytic reaction solution was followed by using water filled gas burette (Figure 14) until no more hydrogen evolution observed (the volume of hydrogen gas evolution was determined from the displacement of water level with certain time intervals at atmospheric pressure which is 693 torr [104]. 


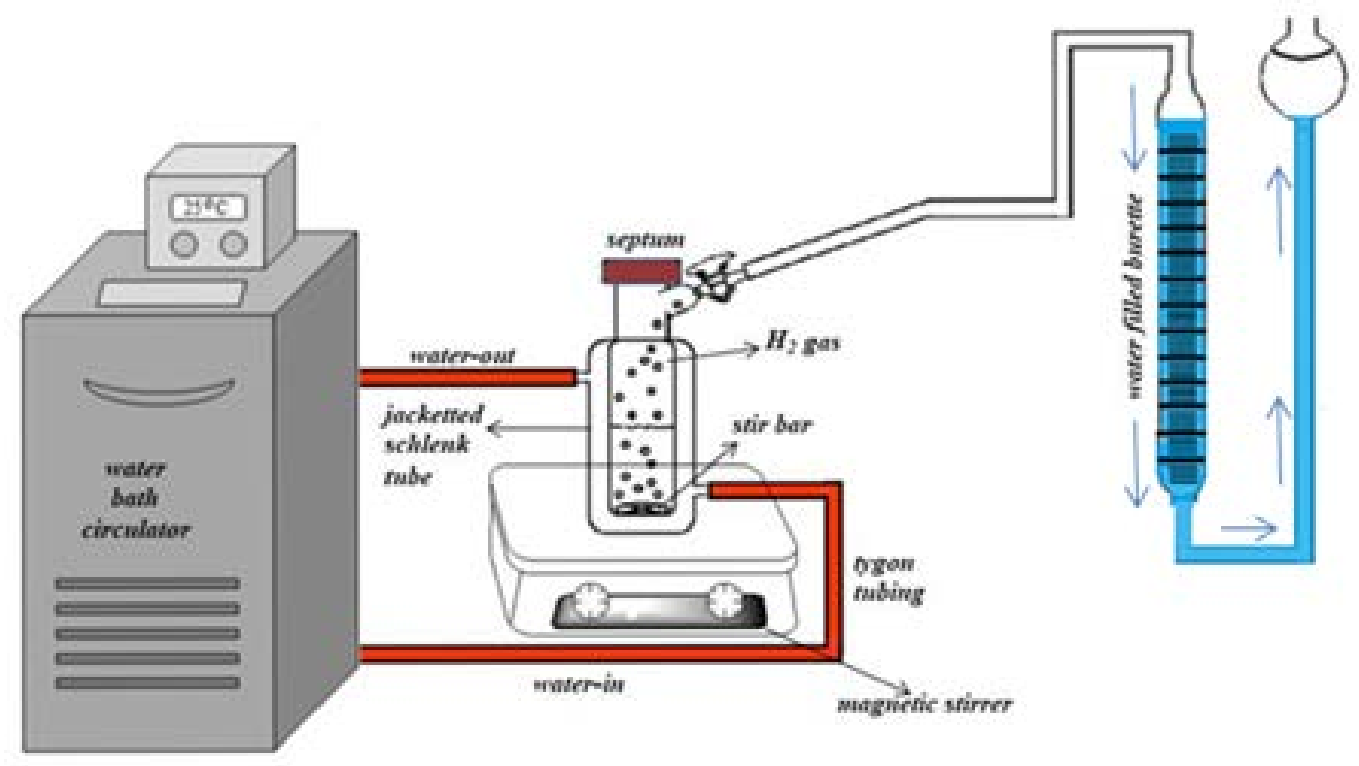

Figure 14. The experimental setup that used in performing the catalytic hydrolysis of hydrazine borane and measuring the hydrogen generation rate.

\subsection{Characterization of PSSMA Stabilized Nickel(0) Nanoparticles}

Powder X-ray diffraction (XRD) patterns were obtained on a Bruker AXS D8Advanced diffractometer with $\mathrm{Cu} K \alpha$ radiation $(\lambda=1.5418 \AA, 40 \mathrm{kV}, 30 \mathrm{~mA})$. TEM and EDX analysises were done on a FEI Tecnai G2 (X-Twin) microscope with an accelerating voltage of $120 \mathrm{kV}$ ( $2 \AA$ resolution). The nanoparticles solution prepared as described in the section 3.2 was centrifuged at $8000 \mathrm{rpm}$ for $15 \mathrm{~min}$. The separated nanoparticles were washed with ethanol and water to remove the excess PSSMA and other residuals. Then, the nanoparticles sample was redispersed in $5 \mathrm{~mL}$ ethanol. One drop of the diluted colloidal solution was deposited on the silicon oxide coated copper grid and evaporated under inert atmosphere. Samples were examined at magnifications between 100 and $600 \mathrm{~K}$. Particle size of the nanoparticles is calculated directly from the TEM image by counting 50 non-touching particles. Size distributions are quoted as the mean diameter \pm the Standard deviation. UVVis electronic absorption spectra of precursor metal salts and PSSMA stabilized metal nanoparticles were recorded in aqueous solution on a Shimadzu UV-2450 UV-Vis double beam spectrophotometer. The XPS analysis performed on a Physical Electronics 5800 spectrometer equipped with a hemispherical analyzer and using monochromatic $\mathrm{Al} \mathrm{K \alpha}$ radiation (1486.6 eV, the X-ray tube working at $15 \mathrm{kV}, 350 \mathrm{~W}$ and pass energy of $23.5 \mathrm{keV}$ ). The solution NMR studies were carried out by using Bruker Avance DPX $400 \mathrm{MHz}$ spectrometer (400.1 MHz for ${ }^{1} \mathrm{H}$ NMR; 100.6 MHz and 128.2 MHz for $\left.{ }^{11} \mathrm{~B} N M R\right)$. $\mathrm{Si}\left(\mathrm{CH}_{3}\right)_{4}$ and $\mathrm{BF}_{3} \cdot\left(\mathrm{C}_{2} \mathrm{H}_{5}\right)_{2} \mathrm{O}$ were used as internal references for ${ }^{1} \mathrm{H}$ and ${ }^{11} \mathrm{~B}$ NMR chemical shifts, respectively. Direct pyrolysis mass spectrometry, DP-MS, analyses were performed on a Waters Micromass Quattro Micro GC Mass Spectrometer with a mass range of 10-1500 Da 
and EI ion source, coupled to a direct insertion probe by recording the $70 \mathrm{eV}$ EI mass spectra at a mass scan rate of $1 \mathrm{scan} / \mathrm{s}$.

\subsection{Synthesis and Characterization of Hydrazine Borane}

Hydrazine-borane $\left(\mathrm{N}_{2} \mathrm{H}_{4} \mathrm{BH}_{3}\right)$ was prepared by the reaction of dihydrazine sulfate with sodium borohydride in cyclic ethers such as tetrahydrofuran (THF) and identified according to literature procedure (eqn (1)) [105]. In the synthesis of hydrazine borane, it is important to use dry reactants to get stable product. For this purpose, sodium borohydride and dihydrazine sulfate were dried under vacuum for enhancing stability of hydrazine borane at $100{ }^{\circ} \mathrm{C}$ and room temperature respectively before usage. Then 20 gram of dried dihydrazine sulfate was dissolved in $200 \mathrm{ml}$ of THF in a vacuumed flask which contains Teflon-coated stir bar (under the inert atmosphere). Then 8.56 gram of $\mathrm{NaBH}_{4}$ was added to the reaction flask which was placed on a magnetic stirrer and the reaction solution was stirred during three days. At the end of the three days, reaction solution was filtered. The white precipitate, which is $\mathrm{Na}_{2} \mathrm{SO}_{4}$, was collected on the filter and removed. The colorless filtrate was dried under vacuum and a dried white crystal which is hydrazine borane was handled.

The melting point of hydrazine borane: $\sim 60{ }^{\circ} \mathrm{C} ; \mathrm{m} / \mathrm{z}=46$ (45.87 calculated for $\mathrm{N}_{2} \mathrm{H}_{4} \mathrm{BH}_{3}$ ); ${ }^{1} \mathrm{H}$ NMR (400.1 MHz, $\left.\mathrm{CD}_{2} \mathrm{Cl}_{2}\right) 5.1 \mathrm{ppm}$ (t, 2, $\mathrm{NH}_{2}-\mathrm{NH}_{2}-\mathrm{BH}_{3}$ ), $3.4 \mathrm{ppm}$ (b, 2, $\mathrm{H}_{2} \mathrm{~N}-\mathrm{NH}_{2}-\mathrm{BH}_{3}$ ), $1.2 \mathrm{ppm}\left(\mathrm{t}, 3, \mathrm{H}_{2} \mathrm{~N}-\mathrm{NH}_{2}-\mathrm{BH}_{3}\right.$ ); ${ }^{11} \mathrm{~B} \mathrm{NMR}\left(128.2 \mathrm{MHz}, \mathrm{H}_{2} \mathrm{O}\right.$ ) -20 ppm (q, $\boldsymbol{B H}_{3}$ ); ATR-IR (selected, $\mathrm{cm}^{-1}$ ) 3310 (s), 3200 (s), 2840 (m), 2650 (m), 2370 (m), 2214 (m), 1620 (s), 1588 (m), 1435 (w), 1332 (m), 1150 (s), 910 (m), 747 (w).

\subsection{Kinetic Study of PSSMA Stabilized Nickel(0) Nanoparticles in Catalytic Hydrolysis of Hydrazine Borane}

Kinetic study of catalytic hydrolysis of HB in the presence of PSSMA stabilized nickel(0) nanoparticles was achieved depending on the different catalyst concentrations, substrate concentrations and temperatures. All experiments were performed in the same way as described in the section 3.2 and the total volume of reaction solution was kept constant at $10 \mathrm{~mL}$. In order to establish the rate law of PSSMA stabilized nickel(0) nanoparticle catalyzed hydrolysis of hydrazine borane, two different sets of experiments were performed at $25.0 \pm 0.5{ }^{\circ} \mathrm{C}$. In the first set of experiments the concentration of nickel kept constant at $3 \mathrm{mM}$ and $\mathrm{N}_{2} \mathrm{H}_{4} \mathrm{BH}_{3}$ concentration was changed in the range of 250, 300, 350, 400, 500, 700 and $1000 \mathrm{mM}\left(115,138,161,184,230,322\right.$ and $460 \mathrm{mg} \mathrm{N}_{2} \mathrm{H}_{4} \mathrm{BH}_{3}$ respectively). In the second set of experiment; $\mathrm{N}_{2} \mathrm{H}_{4} \mathrm{BH}_{3}$ concentration was kept constant at $\left[\mathrm{N}_{2} \mathrm{H}_{4} \mathrm{BH}_{3}\right]=300$ $\mathrm{mM}$ (138 mg HB) and nickel concentration was altered in the range of 2.0, 2.5, 3.0, 4.0 and $5.0 \mathrm{mM}$. 


\subsection{Effect of PSSMA Concentration on the Catalytic Activity of Nickel(0) Nanoparticles}

In order to study the effect of PSSMA concentration on the catalytic activity of nickel nanoparticles in the hydrolysis of $\mathrm{HB}(400 \mathrm{mM})$, catalytic activity tests were performed at $25.0 \pm 0.5{ }^{\circ} \mathrm{C}$ starting with various concentration ratio of [PSSMA]/[Ni] $(0.5,1,1.5$, and 2$)$ for the in-situ generation of nickel nanoparticles.

\subsection{Determination of Activation Parameters of Hydrolysis of HB Catalyzed by PSSMA Stabilized Nickel(0) Nanoparticles}

Activation parameters ( $\mathrm{Ea}^{\mathrm{app},} \Delta \mathrm{H}^{\#, \text { app }}, \Delta \mathrm{S}^{\# \text {,app }}$ ) for the PSSMA-Ni catalyzed hydrolysis of $\mathrm{HB}$ was determined by performing a series of experiments. For this purpose, $300 \mathrm{mM} \mathrm{N} \mathrm{H}_{4} \mathrm{BH}_{3}$ was catalyzed by $3 \mathrm{mM}$ nickel(0) nanoparticles at different temperatures $\left(20,25,30,35\right.$ and $\left.40^{\circ} \mathrm{C}\right)$. At each temperature value, the observed values of rate constants, $k_{\text {obs}}$, were determined for hydrolysis of $\mathrm{N}_{2} \mathrm{H}_{4} \mathrm{BH}_{3}$. By utilizing $\mathrm{k}_{\mathrm{obs}}$ values, Arrhenius and Eyring-Polanyi plots were drawn and activation parameters were calculated.

\subsection{Determination of the Catalytic Life Time of PSSMA-Ni in Hydrolysis of HB}

The catalytic life time of PSSMA-Ni in the hydrolysis of HB was determined by measuring the total turnover number (TTON). Life time experiment was started with $10 \mathrm{~mL}$ solution containing $1.5 \mathrm{mM} \mathrm{Ni}$ and $250 \mathrm{mM} \mathrm{HB}\left(115 \mathrm{mg} \mathrm{N}_{2} \mathrm{H}_{4} \mathrm{BH}_{3}\right)$ at $25.0 \pm 0.5{ }^{\circ} \mathrm{C}$. After all conversion of added $\mathrm{HB}$ completed by checking stoichiometric $\mathrm{H}_{2}$ gas evolution ( 3 mol $\mathrm{H}_{2} / \mathrm{mol} \mathrm{N}_{2} \mathrm{H}_{4} \mathrm{BH}_{3}$ ), a new batch of $115 \mathrm{mg} \mathrm{HB}$ was added and the reaction was kept on in this way until no gas evolution was observed.

\subsection{Carbon Disulfide $\left(\mathrm{CS}_{2}\right)$ Poisoning of PSSMA-Ni and Its Monitoring in the Catalytic Hydrolysis of $\mathrm{HB}$ as Heterogeneity Test}

In order to perform catalyst poisoning experiments a $40 \mathrm{mM}$ stock solution of $\mathrm{CS}_{2}$ in THF was prepared by dissolving $60.5 \mu \mathrm{L}$ of $16.54 \mathrm{M} \mathrm{CS}_{2}$ in total $25 \mathrm{~mL}$ THF in drybox. Then, the catalytic hydrogen generation reaction was started. At the time when $30 \%$ of total hydrogen evolution was provided, $0.2 \mathrm{~mL}$ of $40 \mathrm{mM} \mathrm{CS}_{2}$ solution was taken via syringe and added to the $10 \mathrm{~mL}$ of reaction medium ( $300 \mathrm{mM} \mathrm{HB}, 4 \mathrm{mM}$ nickel(0) nanoparticle). By this way, 0.2 equivalents $\mathrm{CS}_{2}$ were used in order to poison catalyst. When no more hydrogen generation was observed the experiment was stopped.

\subsection{Determination of the Liberated $\mathrm{NH}_{3}$ Gas}

The standard $\mathrm{HCl}$ solution of $0.001 \mathrm{M}, 25 \mathrm{~mL}$ was prepared. The $\mathrm{pH}$ of the solution was measured via $\mathrm{pH}$ meter. Then, the gas generated from the catalytic reaction was passed through $25 \mathrm{~mL}$ standardized solution of $0.001 \mathrm{M} \mathrm{HCl}$ at room temperature. After gas generation was ceased, $\mathrm{pH}$ of the solution was measured again. Then, the $\mathrm{pH}$ difference between two $\mathrm{HCl}$ solutions (before and after the reaction) was compared. 


\section{CHAPTER 4}

\section{RESULTS AND DISCUSSION}

\subsection{In Situ Formation, Isolation and Characterization of PSSMA Stabilized Nickel(0) Nanoparticles in Hydrolysis of Hydrazine Borane}

In situ generation of nickel(0) nanoparticles from the reduction of nickel(II) chloride and catalytic hydrolysis of hydrazine borane were performed in the same medium starting with nickel(II) chloride and hydrazine borane in the presence of poly(4-styrenesulfonic acidco-maleic acid) (PSSMA).

In a typical experiment, polymer (PSSMA) and substrate (HB) were first mixed well in water by stirring at $1000 \mathrm{rpm}$ and then nickel(II) chloride solution was added to the reaction solution. The solution changes its color from pale green to dark brown within less than 30 minutes, indicating the reduction of nickel(II) ions and the formation of nickel(0) nanoparticles. Hydrogen evolution starts after the color change indicating that the nanoparticles formed are active catalyst in the hydrolysis of HB. During the hydrolysis reaction, there was no bulk metal formation observed in reaction medium. This indicates that in the presence of polymeric stabilizer, nickel(0) nanoparticles are stable against the aggregation into bulk metal in reaction solution. The PSSMA-stabilized nickel(0) nanoparticles could be isolated as dark brown powder from the reaction solution by centrifugation, washing with ethanol and water, and drying under inert atmosphere and characterized by XRD, XPS, TEM, EDX and UV-Vis electronic absorption spectroscopy.

The conversion of nickel(II) ions to nickel(0) nanoparticles can nicely be followed in the UV-Vis electronic absorption spectra taken during the reaction (Figure 15). In UVVis spectra, there are three absorption bands of nickel(II) chloride at 395, 650 and $725 \mathrm{~nm}$. These absorption bands gradually disappear upon addition of HB into the solution and a new absorption band grows in concomitantly at $335 \mathrm{~nm}$ which can be assigned to PSSMA stabilized nickel(0) nanoparticles [106]. After reaction started, about 30 min later color change from the original metal precursor solution (pale green) to dark brown was observed. This observation indicates formation of nickel(0) nanoparticles. In UV-Vis spectra, this color change results with a typical Mie exponential decay profile with no obvious absorption peak at 395, 650 and $725 \mathrm{~nm}$ for the PSSMA stabilized nickel(0) nanoparticles [107]. This spectroscopic observation indicates that the reduction of nickel(II) to nickel(0) is observedq within less than 30 min which is a compelling evidence for the reduction of nickel(II) to metallic state and the formation of nanoparticles in the presence of PSSMA in the hydrolysis of HB. 


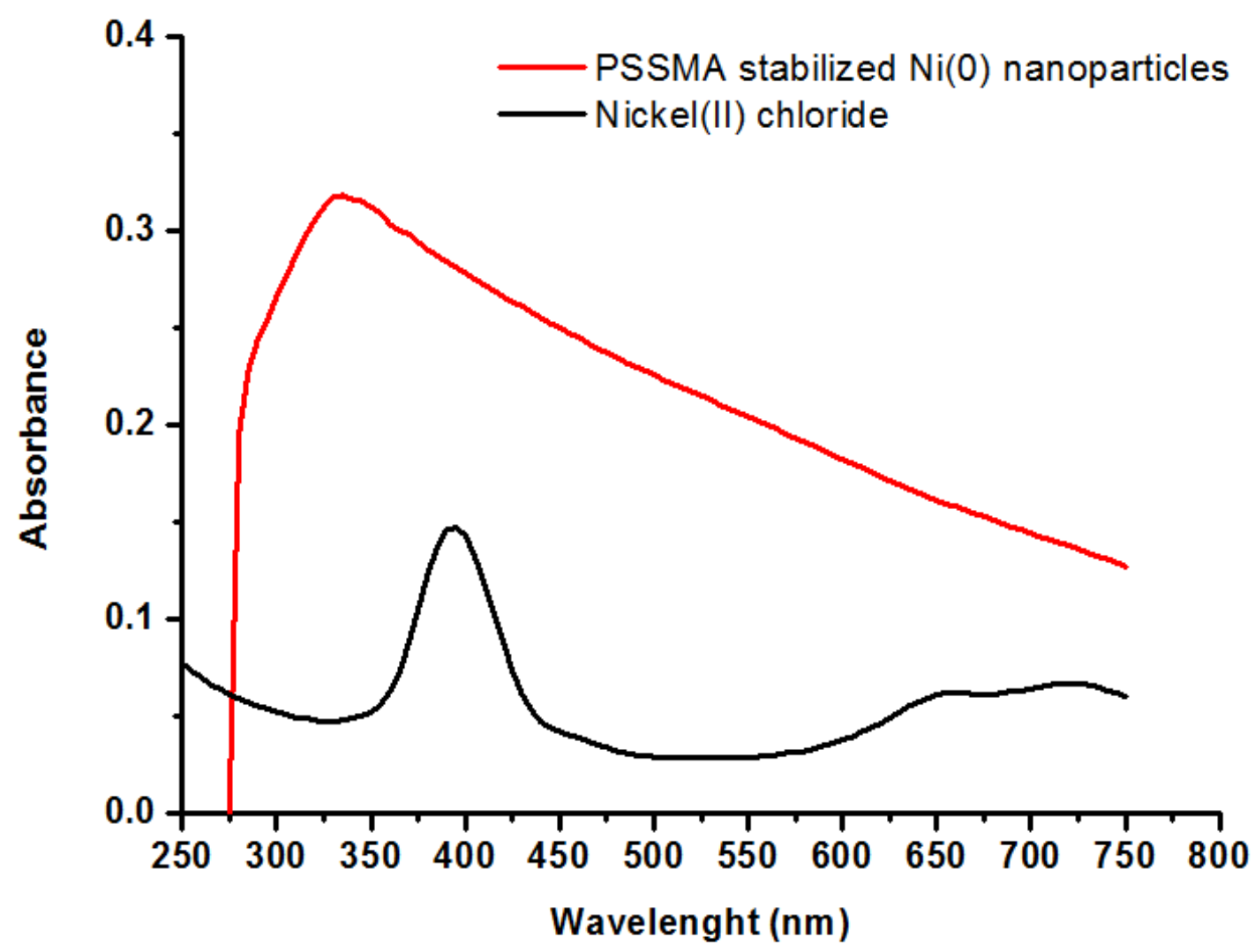

Figure 15. UV-Vis spectra of nickel(II) chloride and PSSA stabilized nickel(0) nanoparticles taken from the $10 \mathrm{~mL}$ solution of $1.5 \mathrm{mM} \mathrm{NiCl}_{2}$ and $250 \mathrm{mM} \mathrm{N}_{2} \mathrm{H}_{4} \mathrm{BH}_{3}$ at $25.0 \pm 0.1^{\circ} \mathrm{C}$.

Nickel(0) nanoparticles formed in situ from the reduction of nickel(II) ions during the hydrolysis of hydrazine borane are stabilized by PSSMA present in solution. They could be isolated as solid from the solution by centrifugation, washing with ethanol to remove the excess PSSMA and other residuals and drying under inert atmosphere.

The crystallinity of the in-situ generated nickel(0) nanoparticles were examined by powder X-Ray diffraction (XRD). The powder XRD pattern of PSSMA-stabilized nickel(0) nanoparticles given in Figure 16 exhibits a broad diffraction at $2 \theta=44.5^{\circ}$ which can be attributed to (111) plane in the face centered cubic structure of nickel(0) nanoparticles [108]. 


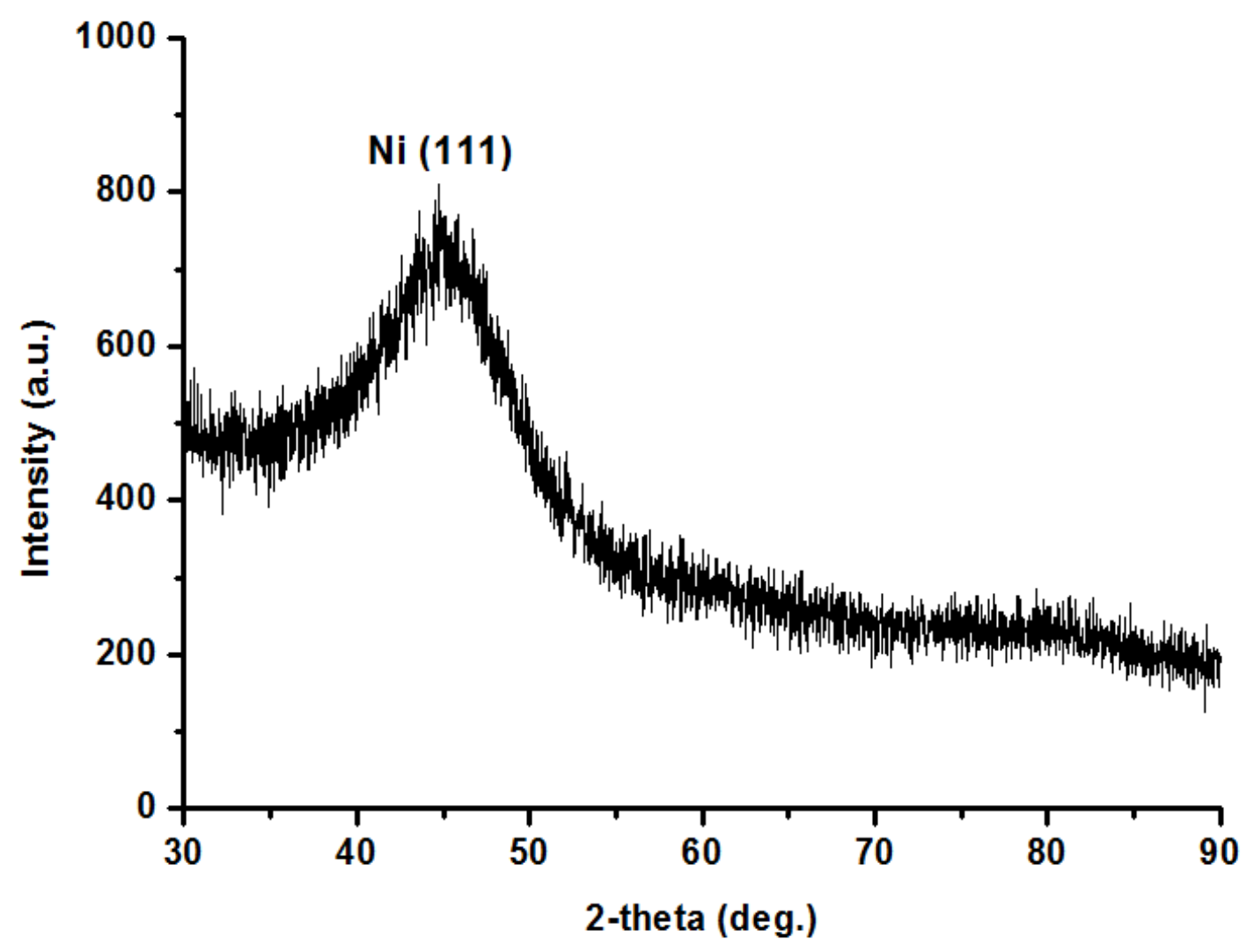

Figure 16. Powder $X$-Ray difraction patterns of in-situ generated PSSMA stabilized nickel(0) nanoparticles isolated from the $10 \mathrm{~mL}$ solution of $5 \mathrm{mM} \mathrm{NiCl}_{2}$ and $300 \mathrm{mM}$ $\mathrm{N}_{2} \mathrm{H}_{4} \mathrm{BH}_{3}$ at $25.0 \pm 0.1^{\circ} \mathrm{C}$.

The transmission electron microscopy (TEM) is one of the most efficient methods in characterization of the metal nanoparticles that gives information about size, shape, and size distribution of nanoparticles. In this study, the morphology and particle size distribution of the PSSMA stabilized nickel(0) nanoparticles were investigated by the transmission electron microscopy (TEM). TEM sample of $\mathrm{Ni}(0)$ nanoparticles was examined at magnifications between 100 and $600 \mathrm{k}$. The inspection of TEM image given in Figure 17A reveals that the nickel(0) nanoparticles are well dispersed. Particle size of the nanoparticles is calculated directly from the TEM image by counting non-touching particles. The particle sizes of 50 untouching particles in the TEM images given in Figure 17A were measured in order to construct the histogram given in Figure 17C. Thus, the particle size of the nickel(0) nanoparticles was calculated. Size distributions are quoted as the mean diameter \pm the Standard deviation. As determined from the histogram, the average particle size of PSSMA stabilized nickel(0) nanoparticles was found as $8.3 \pm 2.3 \mathrm{~nm}$. For the further confirmation of PSSMA stabilized nickel(0) nanoparticles, TEM-EDX characterization technique was also performed from the different range of the sample. The TEM-EDX spectrum of the PSSMA- 
$\mathrm{Ni}$ sample (Figure 17D) shows that nickel is the only element detected in addition to the elements coming from polymeric matrix $(\mathrm{C}, \mathrm{O})$ and $\mathrm{Cu}$ coming from the grid.
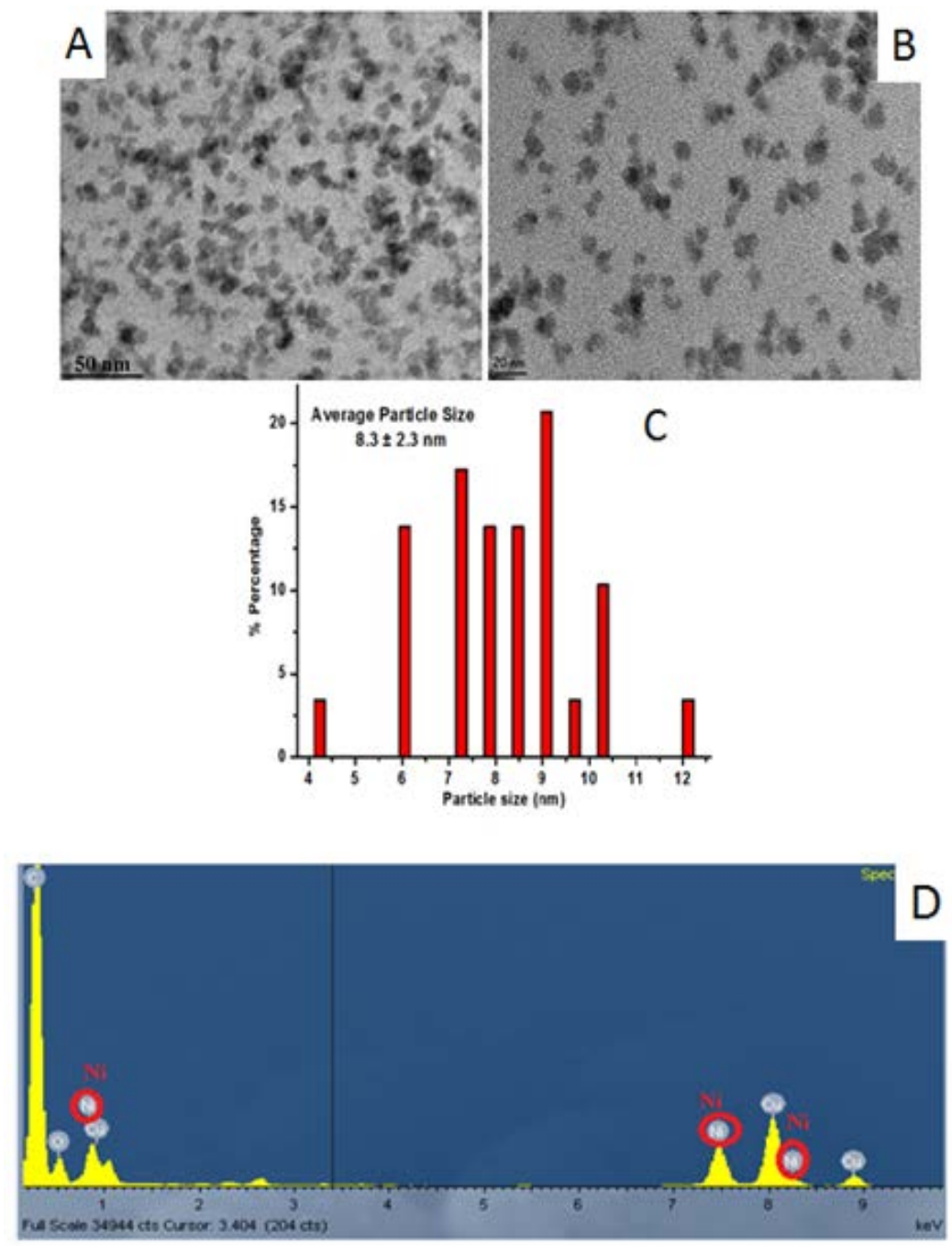

Figure 17. TEM images of PSSMA stabilized nickel(0) nanoparticles (A,B), the corresponding particle size histogram (C), TEM/EDX spectrum of PSSMA-Ni (D) (Nanoparticles were isolated from the $10 \mathrm{~mL}$ solution of $5 \mathrm{mM} \mathrm{NiCl}_{2}$ and $300 \mathrm{mM}$

$$
\mathrm{N}_{2} \mathrm{H}_{4} \mathrm{BH}_{3} \text { at } 25.0 \pm 0.1^{\circ} \mathrm{C} \text { ). }
$$

By the help of X-ray photoelectron spectrometry, the oxidation states of nickel in the PSSMA-Ni sample (after reduction) were investigated. Figure 18A shows the survey-scan XPS spectrum of the PSSMA stabilized nickel(0) nanoparticles. It indicates that nickel is the only element detected in the sample in addition to the framework elements of PSSMA (oxygen and carbon) and nitrogen coming from product of hydrolysis reaction $\left(\mathrm{N}_{2} \mathrm{H}_{5} \mathrm{BO}_{2}\right)$. The high resolution Ni 2p XPS spectrum of PSSMA-Ni sample is given in Figure 18B. This 
spectrum shows two prominent bands at 852 and $869.8 \mathrm{eV}$ attributed to $\mathrm{Ni}(0) 2 \mathrm{p}_{3 / 2}$ and $\mathrm{Ni}(0) 2 \mathrm{p}_{1 / 2}$ by comparing with the values of bulk nickel ( 852.3 and $869.7 \mathrm{eV}$, respectively). There are additional relatively lower intensity bands which observed at slightly higher energy are attributed to oxidation products of nickel metal [109]. These products in high oxidation state of nickel might have been formed by oxidation during the XPS sampling, whereby the nanoparticles are exposed to air for a few seconds. However, the reduction of nickel(II) to nickel(0) was clearly observed also in UV-Vis spectra as mentioned above.
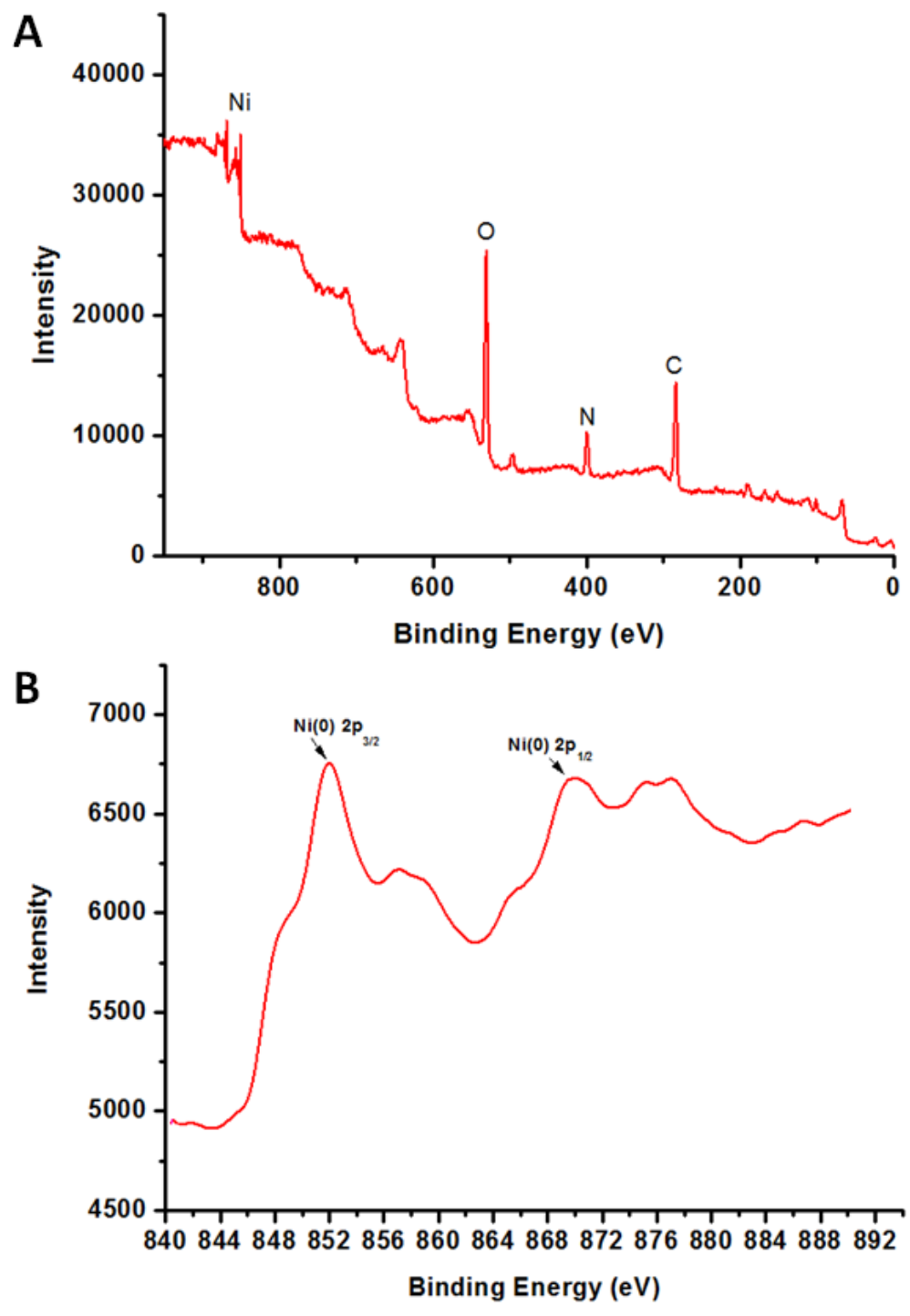

Figure 18. (A) X-ray photoelectron survey scan of PSSMA-stabilized nickel(0) nanoparticles, (B) XPS spectrum of PSSMA-stabilized nickel(0) nanoparticles formed from the reduction of nickel(II) chloride. 


\subsection{Kinetic Evidence for the Formation of the PSSMA Stabilized Nickel(0) Nanoparticles}

The progress of nickel(0) nanoparticles formation and concomitant hydrolytic dehydrogenation of hydrazine borane was followed by monitoring the volume of $\mathrm{H}_{2}$ generated, which was then converted into the equivalent concentration loss of $\mathrm{HB}$, using the known 3:1 $\mathrm{H}_{2} / \mathrm{HB}$ stoichiometry (Equation 2). Figure 19 shows the HB (300 mM) loss versus time plot for the hydrolytic dehydrogenation of $\mathrm{HB}$ starting with nickel(II) chloride $(4.0 \mathrm{mM})$ precatalyst in water at $25 \pm 0.1^{\circ} \mathrm{C}$.

The formation kinetics of the nickel(0) nanoparticles catalyst can be obtained using the hydrolytic dehydrogenation of HB as reporter reaction [103,110,111]. In this study, the heterogeneous catalyst formation was found as not instantaneous, on the contrary, it was found a bit slow. This indicates observation of induction period [112]. During the kinetic studies, all curves in the plots gave nearly sigmoidal shape. The sigmoidal curve consists of a flat, initial induction period during which nucleation is generally believed to occur [103]. The induction period is then followed by fast autocatalytic reduction of the precursor and this indicates fast autocatalytic surface-growth mechanism [113]. In other words, sigmoidal curve can be seen with a long induction period followed by a rapid increase in catalytic activity [114].

Scheme 1 shows the reporter reaction of the hydrolytic dehydrogenation of hydrazine borane, in which $\mathrm{P}$ is the added precursor nickel(II) chloride in solution and Q is the growing $\mathrm{Ni}(0)_{n}$ nanoparticles. The hydrolytic dehydrogenation of $\mathrm{HB}$ will accurately report on and amplifies the amount of $\mathrm{Ni}(0)_{n}$ nanoparticles catalyst, Q, present if the hydrogen generation rate is fast in comparison to the rate of nanoparticles formation. It was shown that the hydrolytic dehydrogenation is almost zero-order in [HB] when the substrate to catalyst ratio is large enough (vide infra) to ensure that the dehydrogenation reporter reaction is fast relative to the rate of slower nanoparticle formation $k_{1}$ and $k_{2}$ steps (Scheme 1). Sigmoidal kinetics can be seen in Figure 19, and fit quite well by the Finke-Watzky 2step, nucleation and autocatalytic growth mechanism of nanoparticle formation [103]. The observation of a sigmoidal dehydrogenation curve and its curve-fit to the slow, continuous nucleation, $\mathrm{P} \rightarrow \mathrm{Q}$ (rate constant $k_{1}$ ) followed by autocatalytic surface growth, $\mathrm{P}+\mathrm{Q} \rightarrow 2 \mathrm{Q}$ (rate constant $k_{2}$ ) kinetics are very strong evidence for the formation of metal( 0 ) nanoparticle catalyst from a soluble transition-metal complex in the presence of reducing agent. The rate constants determined from the nonlinear least squares curve-fit in Figure 19 are $k_{1}=3.13 \times 10^{-6} \mathrm{~min}^{-1}$ and $k_{2}=4.46 \times 10^{-2} \mathrm{M}^{-1} \cdot \mathrm{min}^{-1}$ (the mathematically required correction has been made to $k_{2}$ for the stoichiometry factor of 100 as described elsewhere [110], but not for the "scaling factor"; that is, no correction has been made for the changing the number of nickel atoms on the growing metal surface). These rate constants are for the continuous slow nucleation and autocatalytic growth reaction of $\mathrm{Ni}(0)_{n}$ nanoparticles, respectively, starting with nickel(II) chloride precatalyst $(4.0 \mathrm{mM})$, PMSSA stabilizer $(4.0 \mathrm{mM})$, and hydrazine borane $(300 \mathrm{mM})$ in aqueous solution at $25 \pm 0.1{ }^{\circ} \mathrm{C}$. In this study, the ratio of $k_{2} / k_{1}$ was 
calculated as $1.4 \times 10^{4}$. The large value of $k_{2} / k_{1}$ is indicative of the high level kinetic control in the formation of nickel(0) ions in the presence of stabilizer [115].

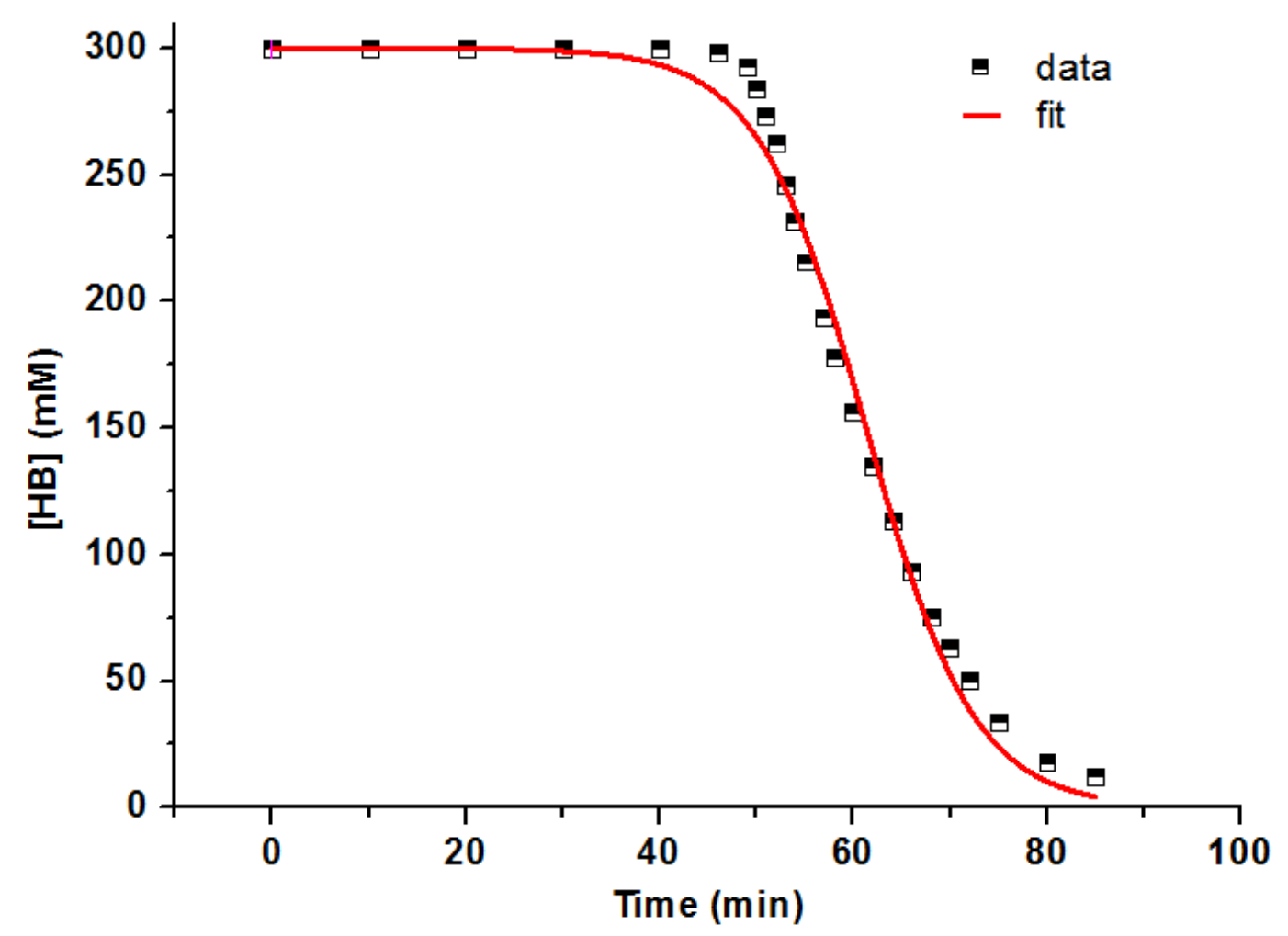

Figure 19. Plot of [HB] loss vs time for hydrolysis of $\mathrm{HB}$ starting with solution of $300 \mathrm{mM}$ $\mathrm{HB}$ and $4 \mathrm{mM} \mathrm{NiCl}{ }_{2}$ at $25 \pm 0.5{ }^{\circ} \mathrm{C}$. The sigmoidal curve fits to the two-step mechanism for nickel(0) nanoparticle formation [115,116].

Scheme 1. Illustration of the hydrolytic dehydrogenation of hydrazine borane as reporter reaction: $\mathrm{P}$ is the precursor nickel(II) ion in the solution and $\mathrm{Q}$ is the growing $\mathrm{Ni}(0)_{\mathrm{n}}$ nanoparticles.

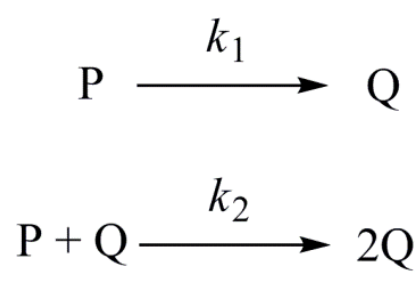

$\mathrm{N}_{2} \mathrm{H}_{4} \mathrm{BH}_{3}(a q)+2 \mathrm{H}_{2} \mathrm{O}(l) \sim$ (fast) $\mathrm{N}_{2} \mathrm{H}_{5}^{+}(a q)+\mathrm{BO}_{2}{ }^{-}(a q)+3 \mathrm{H}_{2}(g)$ 


\subsection{Kinetics of Catalytic Hydrolysis of Hydrazine Borane in the Presence of PSSMA Stabilized Nickel(0) Nanoparticles}

The use of PSSMA as a stabilizer was found to be necessary for the hydrolysis of HB starting with nickel(II) chloride. When PSSMA is not present in this system, the only stabilizing agent is only the weakly coordinating chloride ion which cannot provide enough stabilization for nickel(0) nanoparticles against aggregation. Before studying the kinetics of catalytic hydrolysis of hydrazine borane in the presence of PSSMA-stabilized nickel(0) nanoparticles, the stabilizer concentration had to be optimized regarding the activity and stability of nickel(0) nanoparticles, as they are affected by increasing the concentration of polymer in opposite direction. For this purpose, the nanoparticle formation and hydrolytic dehydrogenation of hydrazine borane was started with nickel(II) chloride (3.0 mM), hydrazine borane $(400 \mathrm{mM})$ and PSSMA in four different concentrations with [PSSMA] / [Ni] ratio of 0.5, 1.0, 1.5 and 2.0. When PSSMA was used in molar ratio of 1.5 or 2.0, neither the reduction of nickel(II) nor the hydrogen evolution was observed, indicating that the concentration of stabilizer relative to that of precursor nickel(II) salt is too high. This high value may result with the formation of the stable complex between nickel metal and polymer stabilizer and as a result polymer may prevent the reduction of nickel(II) ion into its metallic state. On the other hand, the reduction of nickel(II) into its metallic state and hydrogen evolution was observed at a rate of 7.39 and $13.49 \mathrm{~mL} \mathrm{H}_{2} / \mathrm{min}$ in the experiments performed with the ratio of 1.0 and 0.5 , respectively (Figure 20).

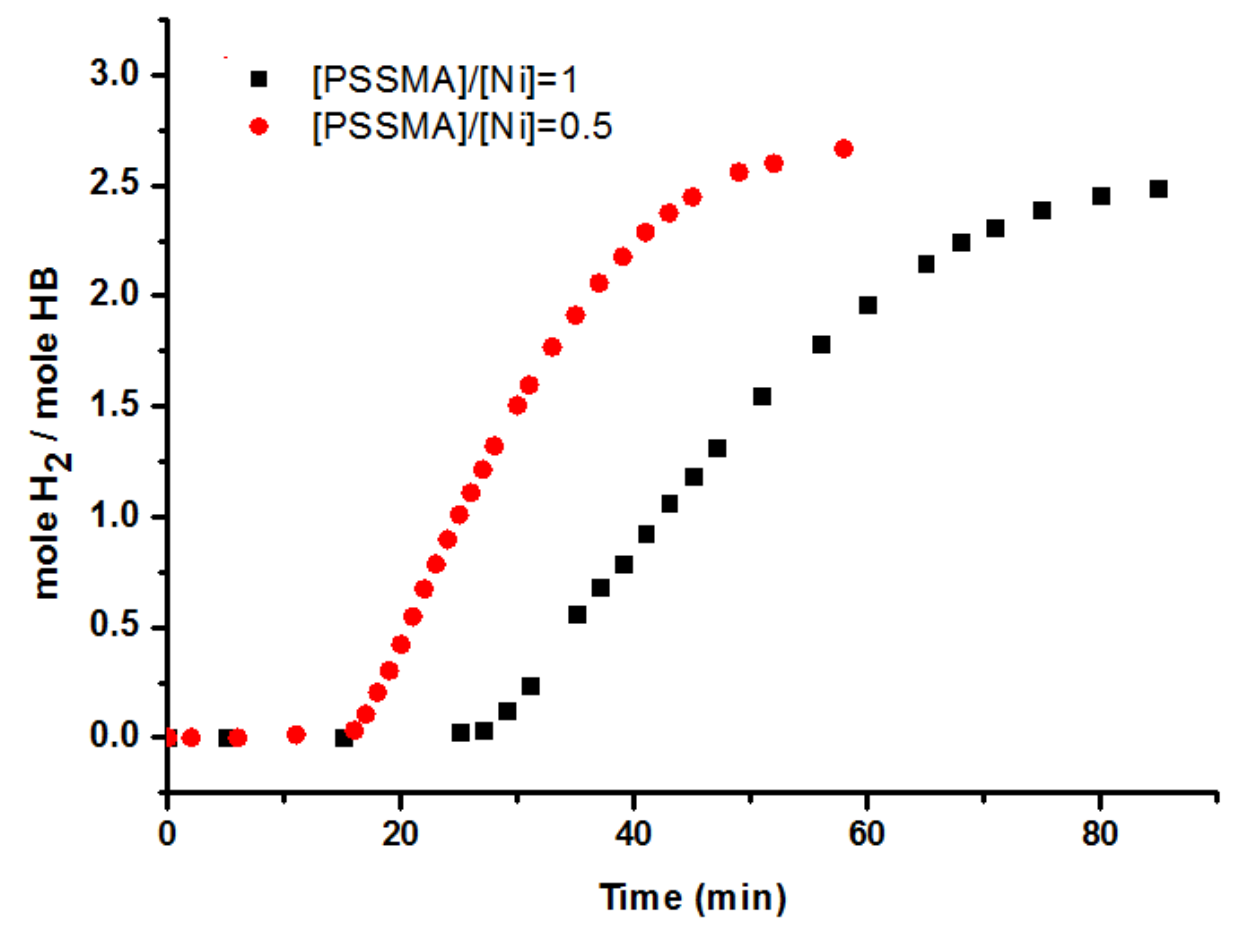

Figure 20. Plots of $\mathrm{mol} \mathrm{H}_{2} / \mathrm{mol} \mathrm{HB}$ versus time depending on the different [PSSMA]/[Ni] ratios for the catalytic hydrolysis of $\mathrm{HB}$. 
Rate of hydrogen generation is higher for low concentration of stabilizer $([$ PSSMA $] /[\mathrm{Ni}]=0.5)$ compared with the ratio of 1.0. However, in low concentration of PSSMA, the nanoparticles are not stable enough and have short catalytic life time to be utilized as catalyst. For this reason, it is concluded that the catalyst obtained in the presence of stabilizer with [PSSMA]/[Ni] ratio of 1.0 has the optimum ratio for hydrolytic dehydrogenation of HB. Consequently, in all the kinetic experiments the polymeric stabilizer was used in the [PSSMA]/[Ni] ratio of 1.0 .

In all the experiments, the molar ratio of the total hydrogen generated from sole hydrolytic dehydrogenation of $\mathrm{HB}$ in the presence of PSSMA stabilized nickel(0) nanoparticles (when [PSSMA]/[Ni] = 1.0) was found as 2.6-3.0 which is close to theoretical value of 3.0 [42]. Figure 21A shows the plot of $\mathrm{mol}_{2}$ generated per mol of HB versus time during catalytic hydrolysis of $300 \mathrm{mM} \mathrm{HB}$ solution in the presence of stabilizer with [PSSMA]/[Ni] ratio of 1.0 and nickel(0) nanoparticles catalyst in different Ni concentration at $25 \pm 0.5^{\circ} \mathrm{C}$. In all experiments, hydrogen evolution starts after an induction period of 20-30 minutes and continues almost linearly until the complete consumption of the substrate hydrazine borane. The hydrogen generation rate was determined from the linear portion of the plot for each experiment and plotted versus the initial concentration of nickel, both axes in logarithmic scale (Figure 21B). This plot gives a straight line with a slope of 0.97 indicating that the hydrolytic dehydrogenation of HB catalyzed by PSSMA-Ni is first order with respect to catalyst concentration. 

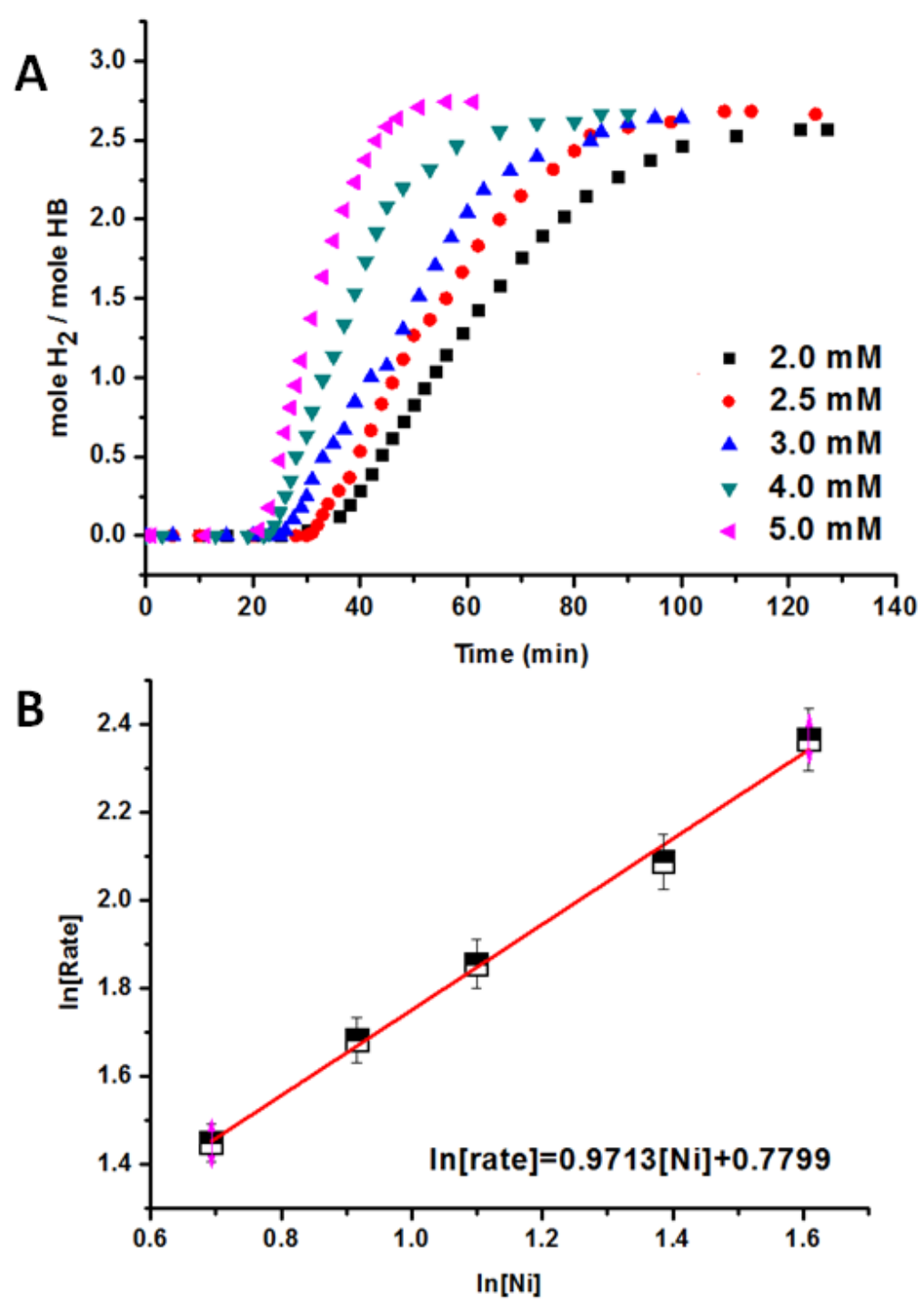

Figure 21. (A) Plot of $\mathrm{mol} \mathrm{H}_{2} / \mathrm{mol} \mathrm{HB}$ versus time (min) for the catalytic hydrolysis of 10 $\mathrm{mL}$ of $300 \mathrm{mM} \mathrm{HB}$ starting with $\mathrm{NiCl}_{2}$ with different nickel concentrations ([Ni] $=2,2.5,3$, 4 and $5 \mathrm{mM}$ ) at $25.0 \pm 0.1^{\circ} \mathrm{C}$, (B) plot of the hydrogen generation rate versus the catalyst concentration, both in logarithmic scale, for the catalytic hydrolysis of $\mathrm{N}_{2} \mathrm{H}_{4} \mathrm{BH}_{3}$.

The effect of substrate concentration on the rate of hydrogen generation from the catalytic hydrolysis of $\mathrm{HB}$ was studied by performing experiments with different concentration of $\mathrm{HB}$ while keeping the [PSSMA]/[Ni] ratio and catalyst concentration constant. Figure 22A shows the plots of mol of $\mathrm{H}_{2}$ generated per mol of $\mathrm{HB}$ versus time during the catalytic dehydrogenation of hydrazine borane started with a [PSSMA]/[Ni] of 1.0 , a catalyst concentration of $3.0 \mathrm{mM} \mathrm{Ni}$ and different substrate concentration at $25 \pm 0.5$ ${ }^{\circ} \mathrm{C}$. In all experiments, hydrogen evolution starts after an induction period of around 25 minutes and continues almost linearly until the complete consumption of the substrate hydrazine borane. It is noteworthy that the induction period doesn't depend strongly on the 
substrate concentration, as expected since the reduction is not affected by the concentration of hydrazine borane which is relatively much higher than that of nickel (more than 100 times). The hydrogen generation rate was determined from the linear portion of the plot for each experiment and plotted versus the initial concentration of hydrazine borane, both axes in logarithmic scale (Figure 22B). This plot gives a straight line with a slope of 0.27 indicating that the hydrolytic dehydrogenation of HB catalyzed by PSSMA-Ni doesn't show strong dependence on the substrate concentration.

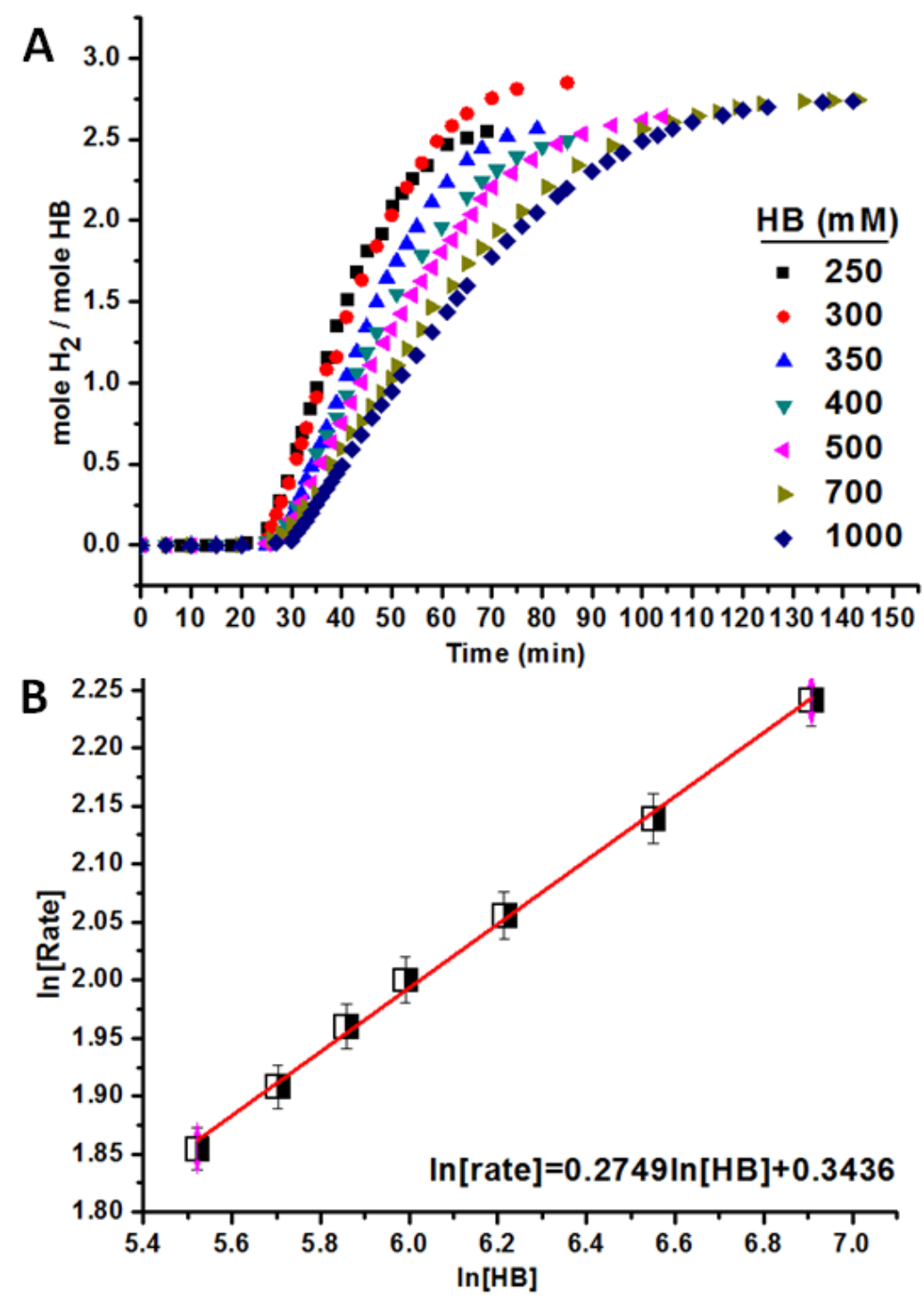

Figure 22. (A) Plot of mol $\mathrm{H}_{2}$ / mol HB versus time (min) for the catalytic hydrolysis of $\mathrm{HB}$ starting with $\mathrm{NiCl}_{2}$ precatalyst $([\mathrm{Ni}]=3.0 \mathrm{mM}$ in $10 \mathrm{~mL}$ water), with different $\mathrm{HB}$ concentrations $\left(\left[\mathrm{N}_{2} \mathrm{H}_{4} \mathrm{BH}_{3}\right]=250,300,350,400,500,700\right.$ and $\left.1000 \mathrm{mM}\right)$ at $25.0 \pm 0.1^{\circ} \mathrm{C}$.

(B) plot of the hydrogen generation rate versus the substrate concentration, both in logarithmic scale, for the catalytic hydrolysis of $\mathrm{HB}$ starting with $\mathrm{NiCl}_{2}$ precatalyst. 
Consequently, the rate law for the catalytic hydrolysis of HB in the presence of PSSMA-Ni was determined as in eqn (6).

$$
-\frac{d\left[N_{2} H_{4} B H_{3}\right]}{d t}=\frac{d\left[H_{2}\right]}{3 d t}=k[N i]\left[N_{2} H_{4} B H_{3}\right]^{0.27}
$$

The hydrolysis of hydrazine borane catalyzed by in-situ generated PSSMA-Ni was also carried out at different temperatures in order to determine the activation parameters $\left(E_{\mathrm{a}}^{\text {app }}, \Delta H^{\# \text {,app }}\right.$ and $\Delta S^{\# \text {,app }}$ ) for the reaction by using Arrhenius, eqn (7), [117] and EyringPolonyi, eqn (8), [118] equations.

$$
\begin{gathered}
\ln (k)=\frac{-E a}{R T}+\ln (A) \\
\ln \frac{k}{T}=\frac{-\Delta H^{*}}{R T}+\ln \frac{k_{B}}{h}+\frac{\Delta S^{*}}{R}
\end{gathered}
$$

Figure 23 shows the plots of volume of $\mathrm{H}_{2}$ generated versus time during the hydrolytic dehydrogenation of $\mathrm{HB}$ performed at various temperatures $\left(20,25,30,35\right.$ and $\left.40{ }^{\circ} \mathrm{C}\right)$ at the constant concentrations of nickel $[\mathrm{Ni}]=3.0 \mathrm{mM}$, stabilizer $[$ PSSMA] $=3.0 \mathrm{mM}$, and hydrazine borane $[\mathrm{HB}]=300 \mathrm{mM}$. As expected, the rate of hydrogen generation from the hydrolysis of $\mathrm{HB}$ increases with the increase of temperature. It is also noteworthy that as temperature increases, the induction period of reaction decreases, as expected because the reduction of nickel(II) ions by hydrazine borane becomes faster at higher temperature, so the nucleation of nanoparticles. The values of the observed rate constants $\left(\mathrm{k}_{\mathrm{obs}}\right)$ determined from the linear portion of each of the volume of hydrogen versus time plots at five different temperatures were used in the construction of Arrhenius and Eyring plots given in Figure $24 \mathrm{~A}$ and $24 \mathrm{~B}$, respectively. The apparent activation parameters were determined as the activation energy $E_{\mathrm{a}}^{\text {app }}=73 \pm 2 \mathrm{~kJ} / \mathrm{mol}$, the enthalpy change of activation $\Delta H^{\# \text {,app }}=72 \pm 2$ $\mathrm{kJ} / \mathrm{mol}$, and the entropy change of activation $\Delta S^{\#, \text { app }}=-26 \pm 3 \mathrm{~J} / \mathrm{mol} \cdot \mathrm{K}$. The positive value of activation enthalpy and negative value of activation entropy are indicative of an associative mechanism for the hydrolysis of HB catalized by PSSMA stabilized Ni(0) NPs. 


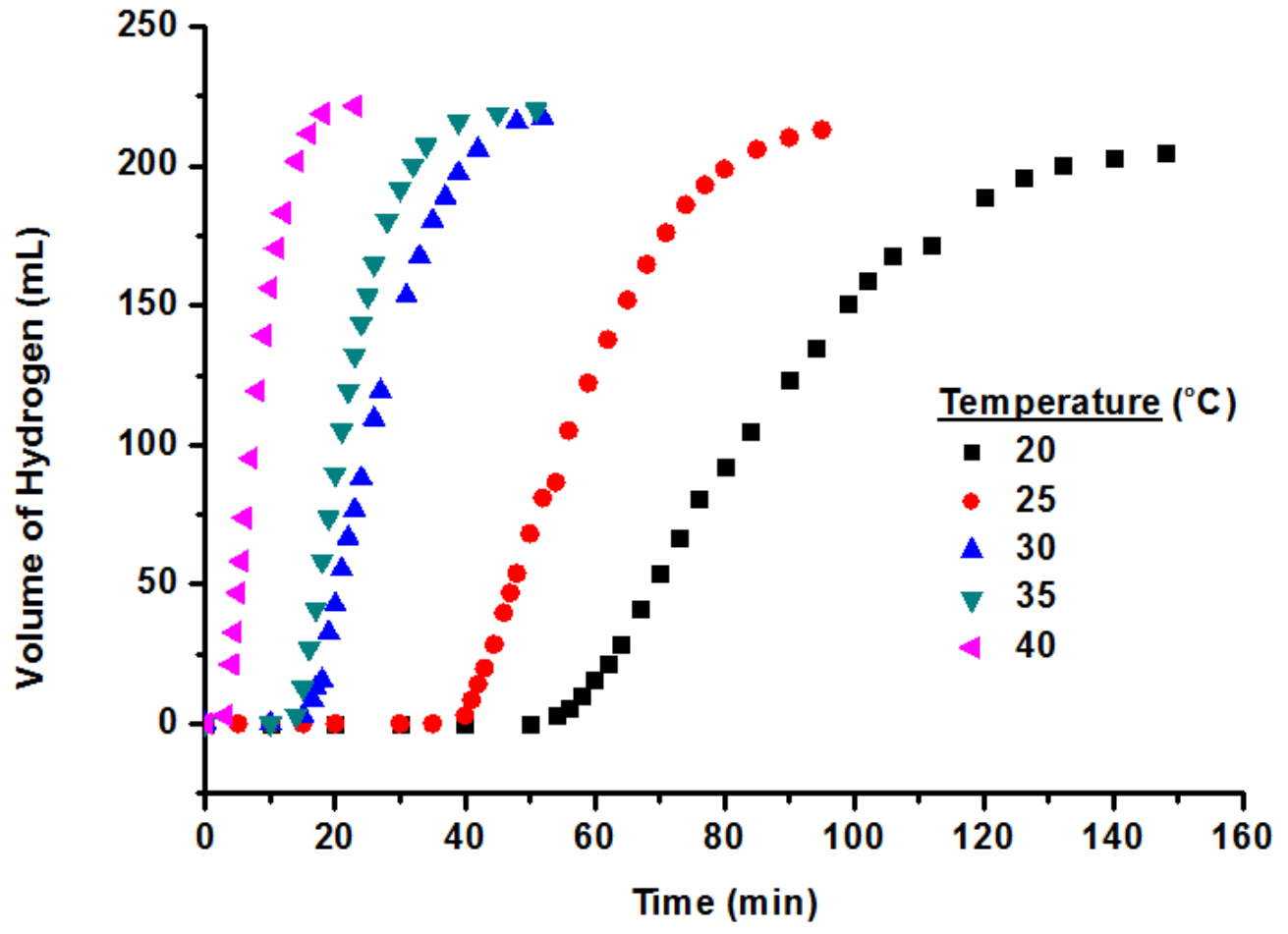

Figure 23. Plot of volume of hydrogen $(\mathrm{mL}$ ) versus time (min) for the catalytic hydrolysis of $\mathrm{HB}\left(\left[\mathrm{N}_{2} \mathrm{H}_{4} \mathrm{BH}_{3}\right]=300 \mathrm{mM}\right.$ in $10 \mathrm{~mL}$ solution) starting with $\mathrm{NiCl}_{2}([\mathrm{Ni}]=3 \mathrm{mM})$ at different temperatures $20,25,30,35$ and $40{ }^{\circ} \mathrm{C}$. 

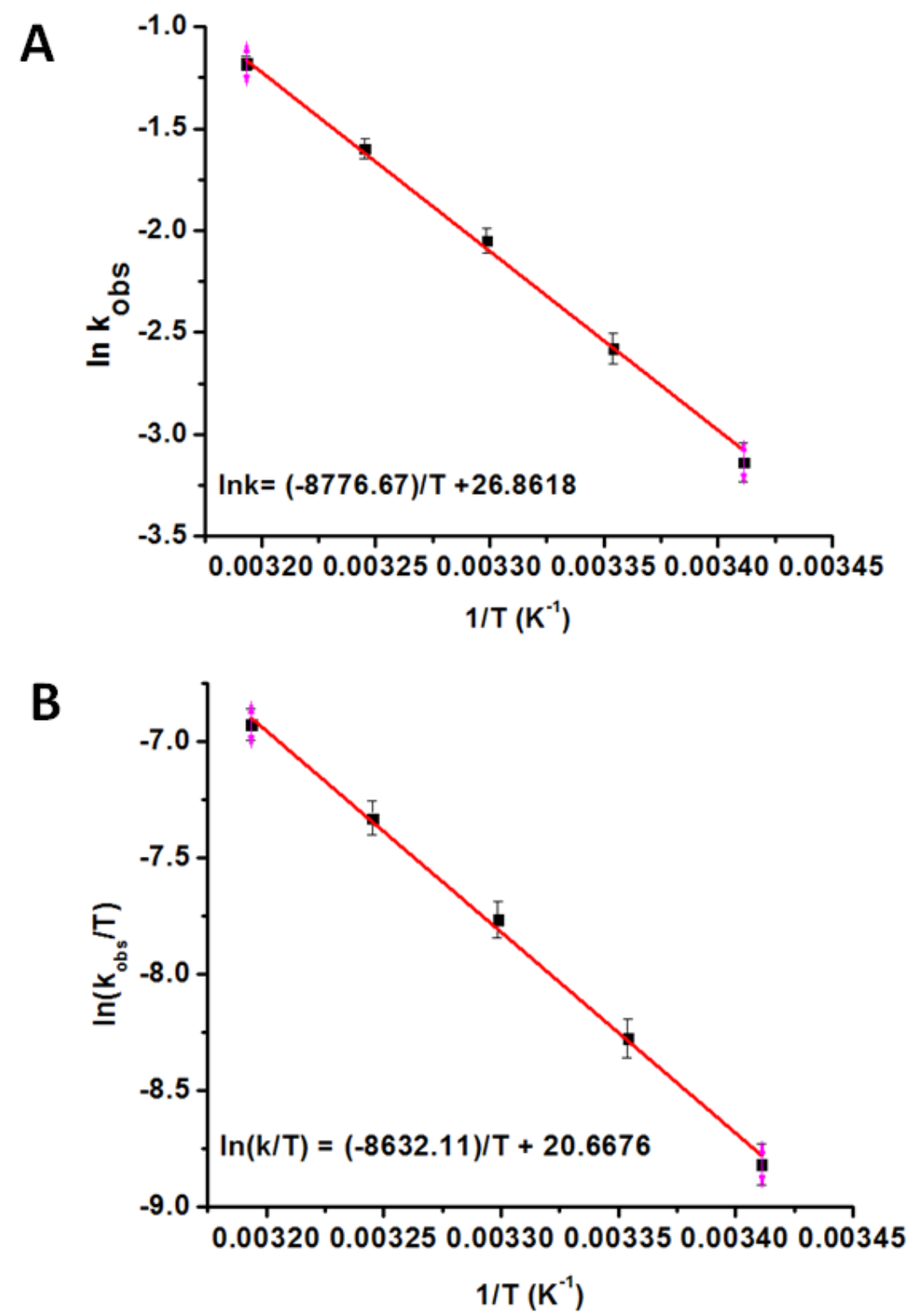

Figure 24. (A) Arrhenius plot, (B) Eyring plot for the hydrolysis of hydrazine borane $\left(\left[\mathrm{N}_{2} \mathrm{H}_{4} \mathrm{BH}_{3}\right]=300 \mathrm{mM}\right.$ in $10 \mathrm{~mL}$ solution) starting with $\mathrm{NiCl}_{2}([\mathrm{Ni}]=3 \mathrm{mM})$ at $20,25,30$, $35,40^{\circ} \mathrm{C}$.

\subsection{Catalytic Lifetime of PSSMA-Ni in Hydrolysis of Hydrazine Borane}

The lifetime of the catalyst, and therefore its stability, are measured in terms of its turnover number. Turnover number is the number of moles of product that a mole of catalyst can convert before becoming deactivated. The lifetime of the PSSMA stabilized nickel(0) nanoparticles was measured by determining the total turnover number for the hydrogen generation from the hydrolysis of hydrazine borane. Such a lifetime experiment was started with $250 \mathrm{mM} \mathrm{HB}, 1.5 \mathrm{mM} \mathrm{Ni}$, and $1.5 \mathrm{mM}$ PSSMA at $25 \pm 0.5^{\circ} \mathrm{C}$. When the complete 
conversion of hydrazine borane was achieved with the liberation of nearly 3 equivalents of hydrogen gas, a new batch of hydrazine-borane was added to reaction flask and hydrogen generation was followed. This procedure was repeated until no more hydrogen evolution was observed. During this experiment, approximately $9 \mathrm{mmol} \mathrm{HB}$ were used in total. At the end of the experiment the total turnover number (TTON, the number of mol of product obtained per mol of catalyst) was determined as given in Figure 25. The PSSMA-stabilized nickel(0) nanoparticles were found to provide 1600 turnovers in hydrogen generation from the hydrolysis of $\mathrm{HB}$ over $18 \mathrm{~h}$ before deactivation at $25 \pm 0.5{ }^{\circ} \mathrm{C}$. In addition to the turnover number, one can determine the catalytic rate of reaction calculating Turnover Frequency (TOF) that is measured in turnovers provided by one mole of catalyst per unit time. In this study, the initial TOF value was found as $3.05 \mathrm{~min}^{-1}$ for the PSSMA-stabilized nickel(0) nanoparticles in hydrogen generation from the hydrolysis of $\mathrm{HB}$ at $25 \pm 0.5{ }^{\circ} \mathrm{C}$ and decreases in the course of reaction. The TOF value of $3.05 \mathrm{~min}^{-1}\left(183 \mathrm{~h}^{-1}\right)$ is comparable with the literature values obtained by using precious metal catalyst such as rhodium, initial TOF $=12000 \mathrm{~h}^{-1}$ [42], and ruthenium $10000 \mathrm{~h}^{-1}$. Since these precious metal catalysts have the high TOF value only for a short time (a few minutes), the much longer lifetime and low price of nickel(0) nanoparticles make them as cost effective catalysts in hydrolytic dehydrogenation of hydrazine borane.

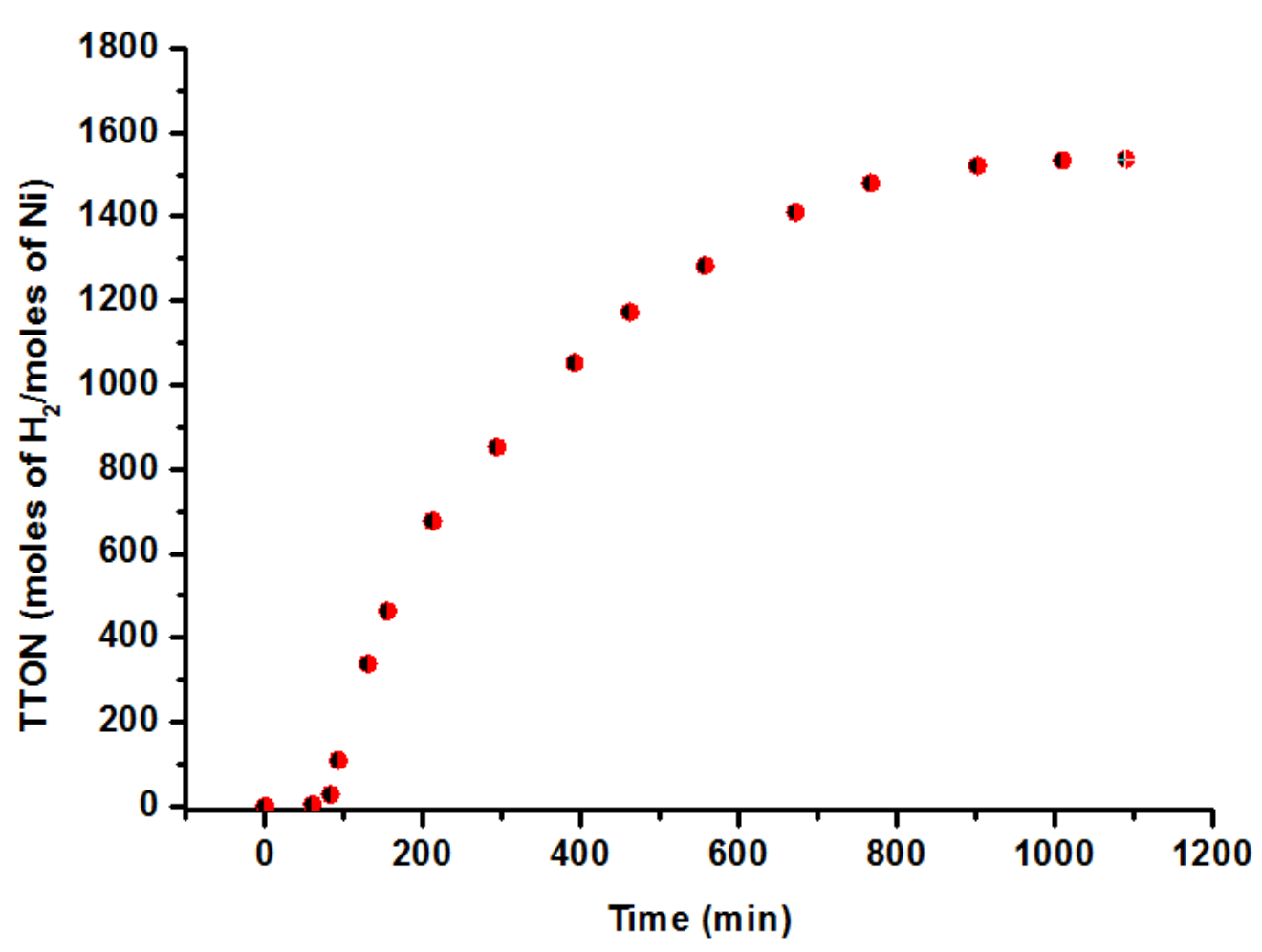

Figure 25. Plot of total turnover number (TTO) versus time for the hydrolysis of hydrazine borane $\left(\mathrm{N}_{2} \mathrm{H}_{4} \mathrm{BH}_{3}\right)$ with a $10 \mathrm{~mL}$ solution of $1.5 \mathrm{mM} \mathrm{NiCl}{ }_{2}$ and $250 \mathrm{mM}$ (for each run) $\mathrm{N}_{2} \mathrm{H}_{4} \mathrm{BH}_{3}$ at $25.0 \pm 0.1^{\circ} \mathrm{C}$. 


\subsection{Carbon Disulfide $\left(\mathrm{CS}_{2}\right)$ Poisoning of PSSMA-Ni and Its Monitoring in the Catalytic Hydrolysis of $\mathrm{HB}$ as Heterogeneity Test}

For answering the question whether the catalyst is "homogeneous or heterogeneous", some poisoning experiments can be done with some chemicals like mercury and carbon disulfide. Mercury poisoning is by far the most commonly used method, however, it is less perfect since an excess of mercury must be used for poisoning experiments [114]. On the other hand, poisoning experiments using added ligands, such as $\mathrm{CS}_{2}, \mathrm{PPh}_{3}$, and thiophene can be powerful for poisoning experiments if it is performed quantitatively. In this study, a poisoning experiment was performed by using carbon disulfide to prove heterogeneity of catalysis. This poison binds strongly to metal centers, thereby blocking access of the substrate to the active site [115]. When less than 1 equivalent $\mathrm{CS}_{2}$ is enough to stop the catalytic reaction, catalysis is predicted to be heterogeneous [119].

In our experiment, only 0.2 equivalent $\mathrm{CS}_{2}$ per mole of catalyst was enough to inhibit catalytic activity of nickel(0) nanoparticles completely. Figure 26 shows $\mathrm{mol} \mathrm{H}_{2} / \mathrm{mol}$ HB versus time plot for the hydrolysis of hydrazine borane $(300 \mathrm{mM})$ catalyzed by PSSMA stabilized nickel(0) nanoparticles $(4.0 \mathrm{mM} \mathrm{Ni})$ with and without 0.2 equivalent $\mathrm{CS}_{2}$ added to the solution at $25.0 \pm 0.5^{\circ} \mathrm{C}$. As seen from the plot, when the $\mathrm{CS}_{2}$ is added to the solution at about 30\% conversion, the hydrogen generation is ceased completely. This is a compelling evidence for the heterogeneity of the hydrolysis of hydrazine borane catalyzed by PSSMA stabilized nickel(0) nanoparticles. 


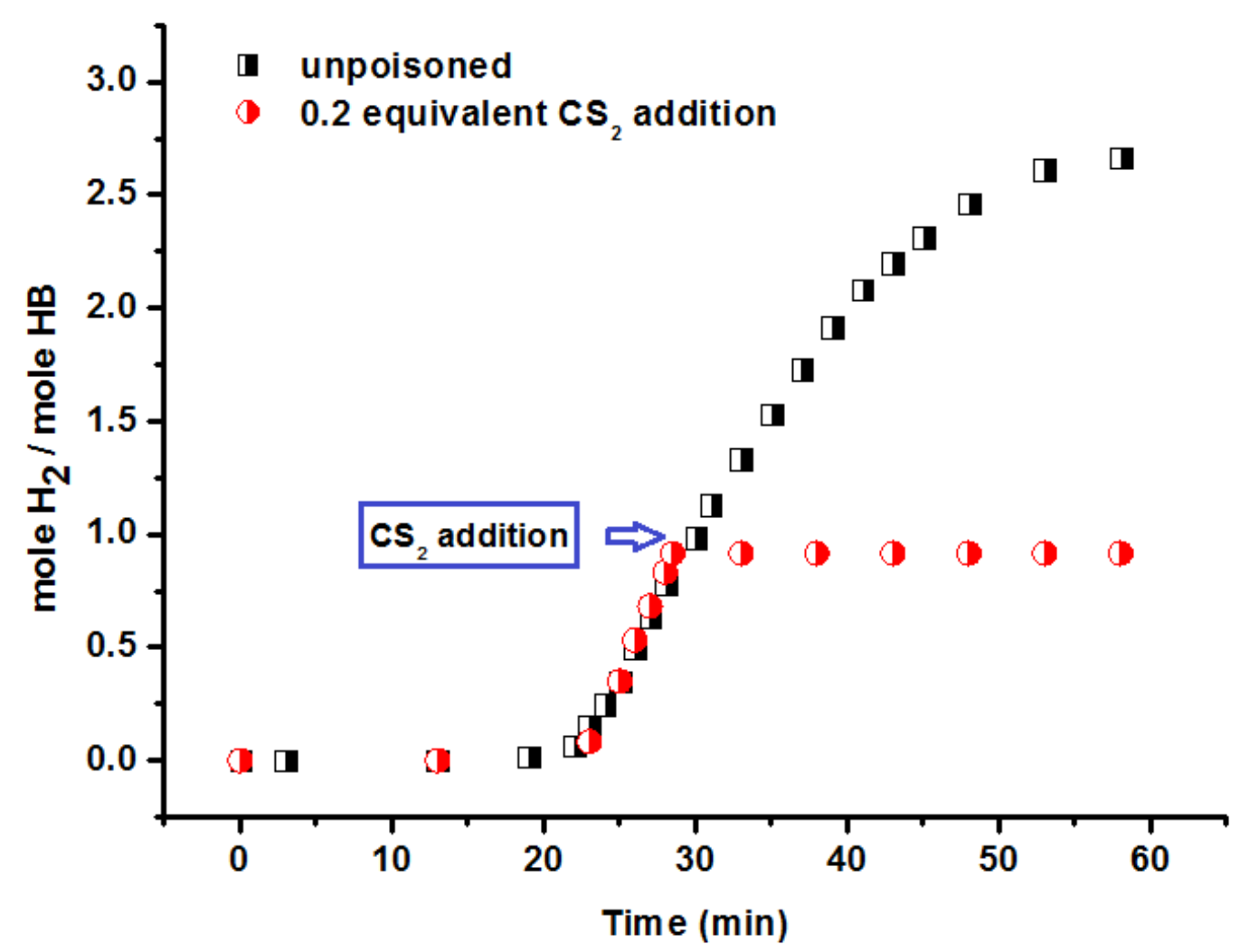

Figure 26. The $\mathrm{mol} \mathrm{H}_{2} / \mathrm{mol} \mathrm{HB}$ versus time (min) plot for the hydrolysis of hydrazine borane $(300 \mathrm{mM})$ catalyzed by PSSMAstabilized nickel $(0)$ nanoparticles $(4 \mathrm{mM} \mathrm{Ni})$ with and without addition of 0.2 equiv. $\mathrm{CS}_{2}$ at $25.0 \pm 0.5^{\circ} \mathrm{C}$.

Moreover, all the hydrolysis reactions of HB catalyzed by PSSMA-Ni, the ammonia generation was checked by passing the gases through a $\mathrm{HCl}$ trap solution, the $\mathrm{pH}$ of which was measured by using a $\mathrm{pH}$ meter. After the complete hydrolysis of $\mathrm{HB}$, no change in $\mathrm{pH}$ of the trap solution was observed indicating that no ammonia is generated during the hydrolytic dehydrogenation reaction. 


\section{CHAPTER 5}

\section{CONCLUSIONS}

In summary, my dissertation on the preparation and characterization of poly(4styrenesulfonic acid-co-maleic acid) stabilized nickel(0) nanoparticles as highly active and cost effective catalyst in hydrogen generation from the hydrolysis of hydrazine borane has led to the following conclusions and insights;

- Highly dispersed nickel(0) nanoparticles stabilized by PSSMA with an average particle size of $8.3 \pm 2.3 \mathrm{~nm}$ were prepared from the reduction of nickel(II) chloride during the hydrolytic dehydrogenation of hydrazine borane in the presence of $1.0 \mathrm{~mol}$ of PSSMA per mol of nickel. They could be isolated from the reaction solution by centrifugation and characterized by a combination of advanced analytical techniques including UVVis., TEM, EDX, XRD and XPS.

- The formation of nickel(0) nanoparticles and the hydrogen generation from the hydrolysis of hydrazine borane occur concomitantly in the same medium at room temperature. The use of hydrogen generation from the hydrolysis of hydrazine borane as reporter reaction provides valuable insights to the formation kinetics of nickel(0) nanoparticles. All the kinetic data, collected for the nanoparticles formation and concomitant hydrolytic dehydrogenation of hydrazine borane catalyzed by PSSMA stabilized nickel(0) nanoparticles fit well to the 2-step mechanism for the nanoparticles formation: the nucleation and then autocatalytic surface growth.

- The resulting PSSMA stabilized nickel(0) nanoparticles formed in-situ during the hydrolysis of hydrazine borane were found to be highly active catalyst in this reaction releasing 2.6-3.0 mol $\mathrm{H}_{2}$ per mol hydrazine borane. They provide 1600 turnovers in hydrogen generation from the hydrolysis of hydrazine borane over $18 \mathrm{~h}$ before deactivation with an initial TOF value of $3.05 \mathrm{~min}^{-1}$ at $25 \pm 0.5^{\circ} \mathrm{C}$.

- The results of quantitative kinetic study on the hydrogen generation from the hydrolysis of hydrazine borane show that the hydrolytic dehydrogenation of hydrazine borane is first order in nickel concentration and the activation energy is $73 \pm 2 \mathrm{~kJ} / \mathrm{mol}$ for the hydrolytic dehydrogenation of hydrazine borane catalyzed by PSSMA stabilized nickel(0) nanoparticles.

Easy preparation, high stability, cost effectiveness and high catalytic performance of the PSSMA-Ni make it promising candidate to be exploited as a catalyst for the portable hydrogen generation systems using hydrazine borane as hydrogen storage material. 


\section{REFERENCES}

[1] U.S Energy of Administration, Annual Energy Review, 2011, http://www.eia.gov/totalenergy/data/annual/pdf/aer.pdf (last access date 03.04.2013).

[2] Moriarty P, Honnery D. Hydrogen's role in an uncertain energy future. Int J Hydrogen Energy, 2009, 34, 31.

[3] Intergovernmental panel on climate change, Special Report on Renewable Energy Sources and Climate Change Mitigation, htth://www.climatechangereports.org/.

[4] Sustainable Energy Green Planet Ethics, http://greenplanetethics.com/wordpress/sustainable-energy-the-future-is-clear-we-mustmove-forward-with-sustainable-energy/ (last access date 03.04.2013).

[5] Niemann MU, Srinivasan SS, Phani R, Kumar A, Goswami DY, Stefanakos EK. Journal of Nanomaterials 2008; doi:10.1155/2008/950967.

[6] Turner J, Sverdrup G, Mann K, Maness PG, Kroposki B, Ghirardi M, Evans R J, Blake D, Int. J. Energy Res, 2007, 32, 379. (b) IAC Report. Lighting the Way towards a Sustainable Energy Future, Interacademy Council, Amsterdam, 2007.

[7] Energyland, New and Renewable Energy, http://www.energyland.emsd.gov.hk/en/energy/renewable/hydrogen.html (last access date 03.04.2013).

[8] U. S. Department of Energy, Basic Research Needs For the Hydrogen Economy, Report of the Basic Energy Sciences Workshop on Hydrogen Production, Storage and Use www.sc.doe.gov/bes/hydrogen.pdf, May 13-15, 2003. (last access date 03.04.2013).

[9] US-DOE, Energy Efficiency \& Renewable Energy, Full Cell Technologies Program, http://www1.eere.energy.gov/hydrogenandfuelcells/pdfs/hydrogenenergyfuture_web.pdf.

[10 ] Stetson NT, U.S Department of Energy, Hydrogen Storage Technologies-A Tutorial with Perspectives from the US National Program, 2010.

[11] International Partnerships for the Hydrogen Economy, Hydrogen storage, http://www.iphe.net/docs/Fact_Sheets/Hydrogen_Storage.pdf (last access date 03.04.2013).

[12] Eberle U, Felderhoff M, Schüth F, Angew. Chem. Int. Ed. 2009, 48, 6608.

[13] Sakintuna B, Lamari-Darkrim F, Hirscher M, Int J Hydrogen Energy, 2007, 32, 1121. 
[14] Jones RH, Thomas GJ, Materials for the Hydrogen Economy, CRC Press, Boca Raton, Fla, USA, 2007.

[15] Topic Paper \#24, Advanced Storage Technologies for Hydrogen and Natural Gas, Working Document of the NPC Future Transportation Fuels Study, 2012.

[16] Stetson NT, Hydrogen Storage, U.S Department of Energy, Annual Merit Review and Peer Evaluation Meeting, 2011.

[17] Aceves SM, Martinez-Frias J, Garcia-Villazana O, Int J Hydrogen Energy, 2000, 25, 1075.

[18] Pehr K, Int J Hydrogen Energy, 1996, 21, 387.

[19] Ogden JM, Kreutz TG, Steinbugler MM, Fuel Cells Bull, 2000, 3, 5.

[20] Aceves SM, Berry GD, Rambach GD, 1998, 23, 583.

[21] Dillon AC, Jones KM, Bekkedahl TA, Kiang CH, Bethune DS, Heben MJ, Nature, 1997, 386.

[22] Hynek S, Fuller W, Bentley J, Int J Hydrogen Energy, 1997, 22, 601.

[23] Chambers A, Park C, Baker RTK, Rodriguez NM, J Phys Chem B, 1998,102,4253.

[24] Rangel CM, Fernandes VR, Slavkov Y, Bozukov L, J Power Sources, 2008, 181, 382.

[25] Rangel CM, Fernandes VR, Slavkov Y, Bozukov L, Int J Hydrogen Energy, 2009, 34, 4587.

[26] (a) Schlapbach L, Züttel A, Nature, 2001, 414, 353; (b) Orimo S, Nakamori Y, Eliseo JR, Züttel A, Jensen CM, Chem. Rev., 2007, 107, 4111.

[27] Zuttel A, Wenger P, Rensch S, Sudan P, Mauron P, J Power Sources, 2003, 118, 1.

[28] Vajo JJ, Skeith SL, J Physical Chem B, 2005, 109, 3719.

[29] US Department of Energy Office of Energy Efficiency and Renewable Energy and The FreedomCAR and Fuel Partnership, Targets for Onboard Hydrogen Storage Systems for light-Duty Vehicles, September 2009. 
[30] Sartbaeva A, Kuznetsov VL, Well SA, Edwards P.P, Energy Environ. Sci., 2008, 1, 79.

[31] Züttel A, Mater Today, 2003, 6, 24.

[32] Ogden JM, Int J Hydrogen Energy, 1999, 24, 709.

[33] Schlapbach L, Züttel A, Nature, 2001; 414:353-8.

[34] Seayad AM, Antonelli DM, Adv Mater 2004; 16:765-77.

[35] Basca R, Laurent C, Morishima R, Suzuki H Lelay M., J Phys Chem B, 2004, 108, 12718.

[36] Schlesinger HI, Brown HC, Finholt AE, Gilbreath JR, Hoekstra HR, Hyde EK, J Am Chem Soc., 1953, 75, 215.

[37] Amendola SC, Sharp-Goldman SL, Janjua MS, Kelly MT, Petillo PJ, Binder M, J Power Sources, 2000, 85, 186.

[38] Amendola SC, Sharp-Goldman SL, Janjua MS, Spencer NC, Kelly MT, Petillo PJ, et al. Int J Hydrogen Energy, 2000, 25, 969.

[39] Demirci UB, Akdim O, Miele P, Int J Hydrogen Energy, 2009, 34, 2638.

[40] (a) Chandra M, Xu Q. J Power Sources 2006; 156:190-4. (b) Chandra M, Xu Q. J Power Sources, 2006, 159, 855. (c) Xu Q, Chandra M. J Power Sources, 2006, 163, 364. (d) Chandra M, Xu Q. J Power Sources, 2007, 168, 135. (e) Zahmakiran M, Özkar S. Appl Catal B, 2009, 89, 104. (f) Durap F, Zahmakıran M, Özkar S. Int J Hydrogen Energy, 2009, 34, 7223. (g) Durap F, Zahmakıran M, Özkar S. Appl Catal A, 2009, 369, 53. (h) Zahmakıran M, Durap F, Özkar S. Int J Hydrogen Energy, 2010, 35, 187. (i) Çalışkan S, Zahmakiran M, Özkar S. Appl Catal B, 2009, 93, 387. (j) Yan JM, Zhang XB, Han S, Shioyama H, Xu Q. Inorg Chem., 2009, 48, 7389. (k) Yamada Y, Yano K, Xu Q, Fukuzumi S. Cu/Co(3)O(4) J Phys Chem C, 2010, 114, 16456. (l) Yan JM, Zhang XB, Akita T, Haruta M, Xu Q. J Am Chem Soc., 2010, 132, 5326. (m) Zahmakıran M, Ayvalı T, Akbayrak S, Çalışkan S, Çelik D, Özkar S. Catal Today, 2011, 170, 76.

[41] Hugle T, Kuhnel M., Lentz D. J Am Chem Soc., 2009, 131, 7444.

[42] Karahan S, Zahmakıran M., Özkar S, Int J Hydrogen Energy, 2011, 36, 4958. 
[43] Çakanyılırım Ç, Demirci UB, Şener T, Xu Q, Miele P, Int J Hydrogen Energy, 2012, 37: 9722-29.

[44] Hamilton CW, Baker RT, Staubitz A, Manners I, 2009 Renewable Energy issue, DOI: 10.1039/b800312m

[45] Kılıç B, Şencanlı S, Metin Ö, J Mol Catalysis A Chemical, 2012, 361, 104.

[46] Peng B, Chen J, Energy Environ. Sci., 2008,1, 479.

[47] Smythe NC, Gordon JC, Eur. J. Inorg. Chem., 2010, 509.

[48] Huang Z, Autrey T, Energy Environ. Sci., 2012, 5, 9257.

[49] Hamilton CW, Baker RT, Staubitz A, Manners I, Chem. Soc. Rev., 2009, 38, 279.

[50] Sit V, Geanangel RA, Wendlandt WW, Thermochim. Acta, 1987, 113, 379.

[51] Metin O, Ozkar S, Energy Fuels, 2009, 231, 3517.

[52] Metin O, Mazumder V, Ozkar S, Sun S, J. Am. Chem. Soc., 2010, 132, 1468.

[53] Metin O, Sahin S, Ozkar S, Int. J. Hydrogen Energy, 2009, 34, 6304.

[54] B.L. Davis, D.A. Dixon, E.B. Garner, J.C. Gordon, M.H. Matus, B. Scott, F.H. Stephens, Angew. Chem., Int. Ed., 2009, 48, 6812.

[55] M.T. Mock, R.G. Potter, D.M. Camaioni, J. Li, W.G. Dougherty, W.S. Kassel, B. Twamley, D.L. DuBois, J. Am. Chem. Soc., 2009, 132, 14454.

[56] Sanyal U, Demirci UB, Jagirdar BR, Sus Chem., 2011, 4, 1731.

[57] Ramachandran PV, Gagare PD, Inorg Chem., 2007, 46, 7810.

[58] Vinh-Son N, Swinnen S, Matus MH, Dixon DA, Phys Chem Chem Phys., 2009, 11, 6339.

[59] Gunderloy FC Jr, Inorg. Chem., 1967, 9, 13.

[60] Hannauer J, Demirci UB, Geantet C, Miele P, Int J Hydrogen Energy, 2012, 37, 10758. 
[61] (a) Singh SK, Lu ZH, Xu Q. Eur. J. Inorg. Chem., 2011, 14, 2232. (b) Jiang HL, Xu Q. Catal. Tod., 2011, 170, 56. (c) Hannauer J, Akdim O, Demirci UB, Geantet C, Herrmann JB, Miele P, Xu Q. Energ. Env. Sci., 2011, 4, 3355.

[62] Pachon LD, Rothenberg G, Appl. Organometal. Chem., 2008, 22, 288.

[63] Schmid G, Nanoparticles: From Theory to Application, Viley-VCH, Weinheim, 2010.

[64] Metin O, Ozkar S, Int. J. Hydrogen Energy, 2011, 36, 1424.

[65] Rakap M, Ozkar S, Int. J. Hydrogen Energy, 2010, 35, 1305.

[66] (a) Rothenberg, G. Catalysis: Concenpts and Green Applications, Wiley-VCH, Weinheim, 2008. (b) Smith, G.V., Notheisz, F., Heterogeneous Catalysis in Organic Chemistry; Academic Press, San Diego, 1999.

[67] Smith, G. V., Notheisz, F., Heterogeneous Catalysis in Organic Chemistry; Academic Press, San Diego, 1999.

[68]Anthonsen, T., Reactions Catalyzed by Enzymes In Applied Biocatalysis, 2. Harwood Academic Publishers, UK, 1999.

[69] Arai N., Ohkuma T., The Chemical Record, 2012, 12, 284.

[70] Pachón DL, 2008, Synthesis and Application of Nano-Structured Metal Catalysts, dissertation, University of Amsterdam, 113.

[71] Aiken III JD, Lin Y, Finke RG, J. Mol. Catal. A, 1996, 114, 29.

[72] Zahmakıran, M., Akbayrak,S., Kodaira,T. Özkar, S., Dalton Trans., 2010, 39, 7521.

[73] (a) Lin Y, Finke RG, J. Am. Chem. Soc., 1994, 116, 8335. (b) Aiken III JD, Finke RG, Chem. Mater., 1999, 11, 1035. (c) Somorjai GA., Borodko YG, Catal. Lett., 2001, 76, 1.

[74] Elghanian R, Storhoff JJ, Mucic RC, Letsinger RL, Mirkin CA, Science, 1997, 277, 1078.

75] Henglein A, Chem. Rev., 1989, 89, 1861.

[76] Schmid G, Simon U, Chem. Commun., 2005, 6, 697.

[77] Glanz J, Science, 1995, 269, 1363. 
[78] Caseri W, Macromol. Rapid Commun., 2000, 21, 705.

[79] (a) Schmid G, Maihack V, Lantermann F, Peschel, S., J. Chem. Soc., Dalton Trans., 1996, 589; (b) Doyle, A., Shaikhutdinov, S. K., Jackson, S. D., Freund, H. J., Angew. Chem., 2003, 42, 5240.

[80] Klabunde, K. J., Stark, J., Koper, C., Park, D., J. Phys. Chem., 1996, 100, 12142.

[81] Roucoux A, Schulz J, Patin H, Chem Rev., 2002, 102, 3757.

[82] Raab C, imkó M, Fiedeler U, Nentwich M, A Gazsó A, Nanotrust dossiers,2011.

[83] Haes AJ, Hall WP, Chang L, Klein WL, Van Duyne PR, Nano Lett., 2004, 4, 1029.

[84 ] Faraday, M., Philos. Trans. R. Soc. London, 1857, 151, 183.

[85] Enustun, B. V.; Turkevich, J., J. Am. Chem. Soc., 1963, 85, 3317.

[86] Turkevich, J.; Kim, G., Science, 1970, 169, 873.

[87 ] Turkevich, J.; Stevenson, P. C.; Hillier, J., Faraday Discuss. Chem. Soc., 1951, 11, 55.

[88] Reetz, M. T.; Helbig, W., J. Am. Chem. Soc., 1994, 116, 7401.

[89] Reetz MT, Helbig W, Quaiser S A. Active metals; Furstner, A., Ed.; VCH:Weinheim, 1996.

[90] Fukuoka A, Sato A, Kodama KY, Hirano M, Komiya S, Inorg. Chim. Acta, 1999, 294.

[91] Klabunde KJ, Youngers G, Zuckerman EJ, Tan BJ, Antrim S, Sherwood PM, Eur. J. Solid State Inorg. Chem., 1992, 29, 227.

[92] Dur’an Pach L, Rothenberg G, Appl. Organometal. Chem., 2008, 22, 288.

[93] Verwey EJW, Overbeek JTG, Theory of the Stability of Lyophobic Colloids, Dover Publications, Mineola, New York, 1999.

[94] Klabunde KJ. (Ed), Nanoscale Materials in Chemistry, Wıley-Interscience Publishers, Newyork, 2001. 
[95] Ninham BW, Adv. Coll. Int. Sci., 1999, 83.

[96] RusselWB, Saville DA, Schowalter WR, Colloidal Dispersions, Cambridge University Press, Cambridge, 1991.

[97] Ott LS, Hornstein BJ, Finke RG, Langmuir, 2006, 22, 935.

[98] Aiken III JD, Finke RG, J. Molecular Catalysis A, 1999, 145, 1.

[99] Hirai, H., Toshima N., In Catalysis by Metal Complexes:Tailored Metal Catalyst, Iwasawa Y (Ed.), Reidel Publishing Company, Dordirect, 1986.

[100] G. Schmid, Nanoparticles: From Theory To Application, Wiley-VCH, Weinheim, 2004.

[101] Zahmakiran M, Özkar S, Inorg. Chem., 2009, 48, 8955.

[102] D.H. Napper, Polymeric Stabilization of Colloidal Dispersions, Academic Press, New York, 1983.

[103] Watzky MA, Finney EE, Finke RG, J. Am. Chem. Soc., 2008, 130, 11959.

[104] Zahmakiran M, Özkar S, J Mol Catalysis A: Chemical, 2006, 258, 95.

[105] Gunderloy FC Jr. Inorg.Chem., 1967, 9, 13.

[106] Creighton JA, Eadon DG. J.Chem.Soc. Faradat Trans, 1991, 87, 3881.

[107] W.Chen, D.Ghosh, J. Sun, M.C. Tong, F.Deng, S.Chen, Electrochimica Acta, 2007, 53, 1150.

[108] Singh SK, Xu Q. Inorg. Chem., 2010, 49, 6148.

[109] Biesinger MC, Payne BP, Lau LWM, Gerson A, Smart RSC. Surface and Interface Analysis, 2008.

[110] Widegren JA, Aiken JD, Özkar S, Finke RG.Chem. Mater., 2001, 13, 312.

[111] Widegren JA, Bennett MA, Finke RG. J. Am. Chem. Soc., 2003, 125, 10301.

[112] Corain B, Schmid G, Toshima N, 2008, Metal Nanoparticles in Catalsysis and Materials Science-The Issue of Size Control, Elsevier, Oxford, 978-0-444-53057-8. 
[113] Özkar S, Finke RG, J. Am. Chem. Soc., 2002, 124, 5796.

[114] Widegren JA, Finke RG, J. Mol. Catal. A: Chem., 2003, 198, 317.

[115] Watzky MA, Finke RG. J. Am. Chem. Soc., 1997, 119, 10382.

[116] Watzky MA, Finke RG. Chem. Mater., 1997, 9, 3083.

[117] Laidler KJ. Chemical kinetics. 3rd ed. UK: Benjamin- Cummings; 1997.

[118] Eyring H. The activated complex in chemical reactions. J Chem Phys., 1935, 3, 107.

[119] Lin Y, Finke RG. Inorg. Chem., 1994, 33, 4891. 
